\title{
The effect of boundary conditions, model size and damping models in the finite element modelling of a moving load on a track/ground system
}

J. Y. Shih ${ }^{1 *}$, D.J. Thompson ${ }^{1}$, A. Zervos ${ }^{2}$

1: Institute of Sound and Vibration Research, Faculty of Engineering and the Environment, University of Southampton, Southampton, SO17 1BJ, UK.

2: Infrastructure Research Group, Faculty of Engineering and the Environment, University of Southampton, Southampton, SO17 1BJ, UK.

*: corresponding author; email: js10e12@ soton.ac.uk

\begin{abstract}
An investigation is presented of the use of finite element models in the time domain to represent a load moving on a railway track on a flexible ground. A systematic study is carried out to compare different sizes and shapes of finite element mesh, different boundary conditions intended for suppressing reflections from the truncated model boundaries, and different models of soil damping. The purpose is to develop guidance to assist in selecting appropriate finite element models for moving load problems. To prevent reflections from the boundaries of the finite domain two approaches are compared. A $40 \mathrm{~m}$ radius hemispherical finite element mesh has been used first with infinite elements around the perimeter. This approach gives good results for a point harmonic load at the centre of the domain but some problems are highlighted when it is used for moving load calculations. An alternative approach has therefore been investigated based on a cuboid mesh. The base was fixed to prevent rigid-body motions of the model and, rather than use infinite elements at the sides, these were also fixed. It is shown that, provided that a suitable damping model is used, the spurious reflections from the sides of the model can be suppressed if the model is wide enough. On the other hand, if infinite elements are used, the calculations are found to be considerably more costly with little added benefit. Different models of soil damping are also compared. It is shown that a mass-proportional damping model gives a decay with distance that is independent of frequency, making it particularly suitable for this application. The length of model required to achieve steady state has been investigated. For a homogeneous
\end{abstract}


half-space it is found that the required length increases considerably in the vicinity of the critical speed, up to $130 \mathrm{~m}$ in the present example, whereas for the layered ground a more modest length is sufficient for all speeds.

Keywords: critical speed; infinite element; Finite Element Method (FEM); moving load; time domain; half-space; layered ground; viscous damping 


\section{Introduction}

Due to the demands of increasing population and environmental concerns, the high-speed train has become an important means of transportation in many countries. However, as the speed of trains approaches that of waves in the ground, track deflections can become large and severe vibration can occur [1]. This is particularly important on soft soil where the wave speeds in the ground are relatively low. For example, there has long been a speed restriction at Stilton Fen on the East Coast Mainline in the UK where the subgrade consists of peat with some clay to a depth of about $7 \mathrm{~m}$. Measurements in 1993 showed that vertical rail deflections increased from about $6 \mathrm{~mm}$ to $12 \mathrm{~mm}$ when the speed was increased from 130 to $185 \mathrm{~km} / \mathrm{h}$ [2]. In 1998, a site measurement was carried out at a location with very soft soil at Ledsgård, Sweden [3], [4]. The vibration of the rail, embankment and ground induced by an X-2000 passenger train increased to very high levels when the train speed was increased to $200 \mathrm{~km} / \mathrm{h}$. The maximum amplitude of track vibration was around 15 to $20 \mathrm{~mm}$ which exceeded the limit for safety and stability. This phenomenon is known as critical velocity behaviour [5]. In planning new high speed lines, particularly in areas of soft soil, it is important to be able to assess potential critical velocity effects and to mitigate against them. Therefore for railway engineering, models are required of moving loads on a track supported on ground.

In early research on the subject of track vibration due to moving loads, the ground was usually neglected or combined with the track model as part of a continuous damped elastic Winkler foundation [1], [6], [7]. In a different approach Eason [8] studied a moving point load applied on the surface of a three-dimensional semi-infinite homogeneous elastic solid. It was shown that the displacement becomes significant when the load speed approaches the Rayleigh wave speed. Krylov [9], [10] included the track and showed that severe rail displacement would occur when the load speed is close to or exceeds the Rayleigh wave speed. Dieterman and Metrikine [11], [12] studied a moving load acting on a finite-width beam supported by an equivalent stiffness to represent the half-space ground. This equivalent stiffness depends on frequency and the wavenumber of waves in the beam. Kaynia et al. [3] developed a model based on Kausel and Roësset's [13] layered ground model and extended this by using Dieterman and Metrikine's method to simulate the dynamic responses from a high-speed train. Good agreement was found between the results from the simulation and measurements at Ledsgård. 
In many papers the track system is assumed to be continuously supported. Vostroukhov and Metrikine [14] compared track models with continuous and discrete supports and found that the response in the vertical direction due to excitation by the train is almost identical in these two cases. Knothe and Grassie [15] indicated that differences between the continuous and discrete support models only occur for calculation frequencies above $500 \mathrm{~Hz}$ in the vertical direction and $400 \mathrm{~Hz}$ in the horizontal direction.

Sheng et al. [16]-[18] developed a more complete analytical model for the coupled track/ground system. The track system included the rail, railpads, sleepers and ballast; this was coupled to a layered elastic ground. The solution was obtained in the wavenumber/frequency domain and included motion of the load. A similar analytical model of a three-dimensional track/ground system, including rail, pad, sleeper, ballast, subgrade and semi-infinite layered ground, was developed by Karlström and Boström [19]. Euler-beam theory was used for the rail whereas the sleepers in this case were assumed to be an anisotropic Kirchhoff plate; the layered ground was again modelled using linear viscoelastic layers. The solution was based on a Fourier transform in time and along the track direction. The embankment vibration in the transverse direction was developed as a Fourier series, and the vibration in the half-space was obtained by a Fourier transform. Recently Costa, et al. [20] developed a simplified approach to assess the critical speed based on Sheng's model which showed good accuracy and has good computational efficiency.

As well as these analytical methods, a wavenumber finite element/boundary element (FE/BE) model was introduced by Sheng et al. [21] and a similar 2.5D FE/BE track-ground model was introduced by François et al. [22]. Both of these methods used finite elements to model the track and boundary elements to model the soil and they operate in the frequency domain. The use of boundary elements allows the infinite medium to be included, avoiding reflections at the edge of the modelled domain. As an alternative, a 2.5D finite element/infinite element method was developed by Yang et al. [23] and used to study the transmission of vibration induced by trains moving at different speeds [24]. Again, the infinite elements are used to minimise the influence of the domain boundaries.

As has been seen, many of these models involve calculations of the dynamic response in the frequency domain or involve a transfer from the frequency to the time domain by means of a 
Fourier transform. This approach is restricted to linear steady-state problems In order to include non-linear effects in the track or soil, or transient effects, a time-domain approach will be required [25]. A number of authors, e.g. [25]-[27], have used the finite element method for modelling ground-borne vibration induced by high-speed trains in order to consider soil nonlinearity. However, modelling the unbounded medium is the most difficult issue with such a method. Wave reflections will occur at the boundaries, which can influence the results unless a very large model is applied [28], [29].

A special technique, called the moving finite element method, was developed by Lane et al. [30] to model the track/ground response due to a moving vehicle. In this approach the soil material moves relative to the FE mesh after a certain number of time steps, so that the vehicle does not need to move relative to the mesh. This gives a better efficiency and smaller demand of model size. However, this approach is complicated and difficult to embed in commercial software

An alternative, in which an artificial boundary is created to absorb the reflections, has been widely implemented in finite element modelling of ground-borne vibration induced by moving dynamic loads. A three-dimensional finite element model with three-dimensional viscoelastic dynamic artificial boundary was implemented by Zhai et al. [31] and Shan et al. [32]. However, the accuracy of such a viscoelastic artificial boundary is very sensitive to the spring stiffness acting in the radial direction, which can result in severe oscillation. Furthermore, the geometry of the boundary is still an important issue.

The perfect matching layer approach was implemented by Wang et al. [33] to investigate the vibration from maglev train-guideway-tunnel-soil interaction. A special scheme that uses several layers of elements with increasing size and material damping to attenuate the incident wave was implemented by Gardien et al. [34] to investigate the element size, soil stiffness, damping, boundary conditions and finite element method software for soil vibrations from railway tunnel. However, the parametric study was based on a two-dimensional model and the assessment of critical speed effect was not investigated. A time-dependent absorbing boundary was developed by $\mathrm{Ju}$ et al., for complex modelling and good agreements were found compared with site measurements [35], [36]. Dashpot absorbing elements have been commonly used in combination with the finite element method due to their simple theory and good absorption ability [37] and these have been implemented in the commercial FE software 
ABAQUS [38]. Kouroussis [39], [40] produced a model of the track/ground system using a hemispherical finite element model of the soil together with the infinite elements in ABAQUS; good agreement was found compared with the results from measurements [39], [41]. A similar approach was used by Connolly et al. [42] in which a coupled vehicle/track/ground interaction model was implemented in ABAQUS. The ground was modelled using an elongated hemisphere in order to limit the depth of the model. Calculations were performed in the time domain and were verified using experimental data. Other studies have used a cuboid FE models combined with infinite elements to determine the dynamic response from the train-track system by using a similar approach [43]-[46]. None of these artificial boundaries allow the incident wave to be transmitted perfectly at the boundary in every situation. Specific restrictions are required for different artificial boundary models to obtain better accuracy. The infinite element method (dashpot absorbing elements) is chosen as an example here to investigate the use of the commercial software, ABAQUS.

The infinite element method has become popular as a means of simulating an infinite domain due to its simplicity and the ease with which it can be combined with the finite elements. Furthermore, it can be used both in the time and frequency domains and soil nonlinearity can readily be considered within the FE domain. However, the absorption efficiency of the infinite elements relies on the domain geometry. Usually they should be located in the far field and orientated perpendicular to the incident wave field. Even though an improved development of this method was introduced in [47] by modifying the expression of the energy ratio, the results are still strictly related to the incident angle of the wave propagation. Furthermore, a small reflected component may still exist due to this non-perfect absorption, requiring a larger model to obtain improved accuracy [39].

Another issue has been found when modelling a moving load in the time domain by using the FE method [44], [45]. It is found that the response to the moving load requires a certain length of calculation for the waves to develop fully which depends on the geometrical spreading and the propagation velocities of the different waves. Consequently, the results at the end of the model are usually used as being more representative of the actual response. However, the distance required varies with the speed of the travelling load as well as the soil properties. 
The purpose of the current study is to investigate the influence of the finite element modelling strategy on the results for a moving load on a track/ground system. In particular, a systematic study is carried out to compare different sizes and shapes of finite element mesh, as well as different boundary conditions of the truncated model intended for suppressing reflections, and different models of soil damping. The purpose is to use models of relatively simple geometry to develop guidance to assist in selecting appropriate models for moving load problems that can give reliable results without requiring excessive computation times. Although the study is based on using a commercial software package, the issues addressed are not specific to this software. A hemispherical mesh is first considered with infinite elements around the boundary of the mesh. This is compared with alternative strategies based on a cuboid mesh with and without infinite elements. An investigation is carried out into the size of model required to obtain steady-state results in the time domain. Different damping models for the soil are also compared and results are presented for both a homogeneous soil and a layered soil. Comparisons are made with an established 2.5D FE/BE model which provides the steady-state response [21].

\section{Numerical models}

A three-dimensional time domain track/ground model is presented that has been developed in the FE software ABAQUS. The infinite elements used in ABAQUS are introduced in Section 2.1. Two different types of ground mesh are compared, as described in Sections 2.2 and 2.3. In each case the mesh has been produced, including the corresponding infinite elements, by using dedicated Python code to allow different sizes of mesh to be generated automatically. The track model is introduced in Section 2.4 including the values of the various parameters and the element types used. A wavenumber FE/BE model used for comparison is described in Section 2.5.

\subsection{Viscous boundaries}

The local transmitting boundary based on the formulation by Lysmer and Kuhlemeyer [37] is used for the infinite element in ABAQUS in order to minimise wave reflections from the boundary of finite element domains. The incident waves are absorbed at the boundary by many infinitesimal dashpots which are orientated normal and tangential with respect to the boundary. These are designed to absorb plane waves, considered independently in three 
directions, by defining distributed equivalent dampers on the boundary. These can be defined in terms of load coordinates ( $x$, normal and $y, z$ tangential) as [38]

$$
\left\{\begin{array}{l}
\sigma_{x x}=-d_{p} \dot{u}_{x} \\
\sigma_{x y}=-d_{s} \dot{u}_{y} \\
\sigma_{x z}=-d_{s} \dot{u}_{z}
\end{array}\right.
$$

where $\sigma_{x x}$ etc are stresses, $\dot{u}_{x}$ etc are velocities and the equivalent damping values, $d_{p}, d_{s}$ are given as

$$
\left\{\begin{array}{l}
d_{p}=\rho c_{p} \\
d_{s}=\rho c_{s}
\end{array}\right.
$$

where $\rho$ is the material density and $c_{p}, c_{s}$ are the wave speeds of the P-wave (longitudinal wave) and the S-wave (shear wave). These relations can be derived by assuming linear elastic stress-strain relations and zero wave reflection at the boundary for an incident plane wave of each type. In reality the incident field is not a plane wave and this leads to some residual reflection from the boundary [37], [38].

\subsection{Hemispherical ground mesh}

In the first type of mesh considered here, the ground is represented as a hemisphere of finite elements surrounded by infinite elements, as shown schematically in Fig. 1(a). Meshes with various diameters have been compared: $10 \mathrm{~m}, 20 \mathrm{~m}$ and $40 \mathrm{~m}$. Use is made of symmetry in the $x-y$ plane to limit the model to a quarter sphere. Four-node tetrahedral elements are used for the ground model and eight-node linear infinite elements are introduced on the boundary. A layer of eight-node brick elements is arranged around the perimeter of the ground to interface with the infinite elements, as shown in Fig. 1(b).

In wave propagation problems, the element size should be selected according to the highest frequency in the simulation. Higher frequencies correspond to smaller wavelengths, so the maximum element size should be chosen according to the maximum frequency of interest. The maximum element size is controlled by the shear wavelength $\lambda_{s}$; generally at least 6 elements are required per wavelength, although some authors suggest higher numbers [48], [49]

$$
l_{e} \leq \frac{\lambda_{s}}{6}
$$


where $l_{e}$ is the maximum element length. Consequently, due to the relationship between wavelength and frequency, the upper limit of the frequency range can be derived as

$$
f_{\max } \leq \frac{c_{s}}{6 l_{e}}
$$

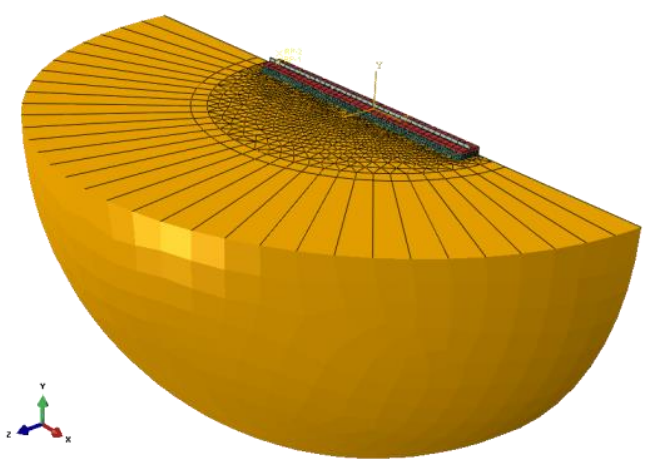

(a)

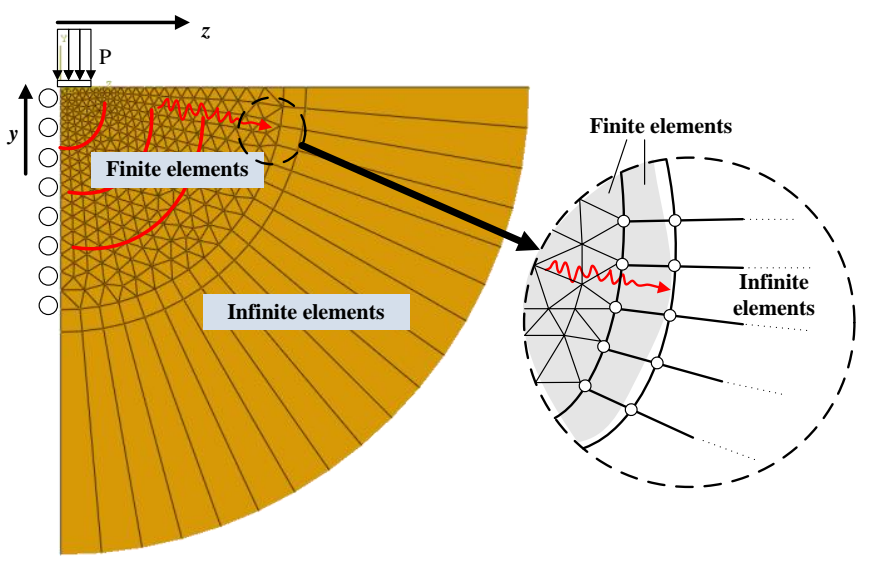

(b)

Figure 1. Ground model; (a) hemispherical ground model; (b) schematic view of model geometry

However, the case of a moving load is a transient problem which does not have a specific frequency range from which to determine the element size. Furthermore, the waves are attenuated as they propagate outwards from the load position. The response at the track is mainly dominated by the elements that are close to the excitation point whereas elements further away have a smaller influence, provided that the outgoing wave field is modelled correctly. Moreover, higher frequencies are generally attenuated more rapidly with distance than low frequencies. A graded mesh is considered here as such a mesh was found by Zerwer et al. [50] to provide a better accuracy for Rayleigh wave problems than a uniform mesh. This is due to most of the Rayleigh wave energy being located within one wavelength of the surface, which reduces in size as frequency increases. Four-node tetrahedral elements are used with size $0.25 \mathrm{~m}$ for the region close to the track, which gives around 6 nodes per Rayleigh wavelength at $40 \mathrm{~Hz}$. The size increases gradually to $1 \mathrm{~m}$ at the outer boundary. Four-node brick elements (C3D8) are used to connect appropriately with eight-node linear, one-way infinite elements (CIN3D8), as shown in Fig. 1. A calculation time step $d t$ of $0.001 \mathrm{~s}$ is chosen for all the time-domain simulations, based on the Courant-Friedrichs-Lewy (CFL) condition [51]

$$
d t \leq \frac{l_{e}}{c_{p}}
$$


where $l_{e}$ is the minimum element length.

Two different sets of ground parameters are considered as examples. The first represents a soft homogeneous half-space with a shear wave velocity of $60 \mathrm{~m} / \mathrm{s}$ and corresponding Rayleigh wave speed of $57 \mathrm{~m} / \mathrm{s}$. The properties of the ground are listed in Table 1 . The second represents a layered half-space with a $2 \mathrm{~m}$ deep layer of soft soil over a stiffer halfspace. The properties of this soil are listed in Table 2. Although these soil properties are not related to a particular location they are chosen to represent a site with a low critical velocity similar to Ledsgård.

Table 1. Half-space ground model properties

\begin{tabular}{|c|c|}
\hline Young's Modulus, $E$ & $19.2 \mathrm{MN} / \mathrm{m}^{2}$ \\
\hline Poisson's ratio, $v$ & 0.333 \\
\hline Mass density, $\rho$ & $2000 \mathrm{~kg} / \mathrm{m}^{3}$ \\
\hline P-wave speed, $c_{p}$ & $120 \mathrm{~m} / \mathrm{s}$ \\
\hline S-wave speed, $c_{s}$ & $60 \mathrm{~m} / \mathrm{s}$ \\
\hline
\end{tabular}

Table 2. Layered half-space ground model properties

\begin{tabular}{|c|c|}
\hline \multicolumn{2}{|c|}{$\begin{array}{l}\text { First-layer properties } \\
\end{array}$} \\
\hline Young's Modulus, $E$ & $19.2 \mathrm{MN} / \mathrm{m}^{2}$ \\
\hline Poisson's ratio, $v$ & 0.333 \\
\hline Mass density, $\rho$ & $2000 \mathrm{~kg} / \mathrm{m}^{3}$ \\
\hline P-wave speed, $c_{p}$ & $120 \mathrm{~m} / \mathrm{s}$ \\
\hline S-wave speed, $c_{s}$ & $60 \mathrm{~m} / \mathrm{s}$ \\
\hline Depth & $2 \mathrm{~m}$ \\
\hline \multicolumn{2}{|c|}{ Second-layer properties } \\
\hline Young's Modulus, $E$ & $76.8 \mathrm{MN} / \mathrm{m}^{2}$ \\
\hline Poisson's ratio, $v$ & 0.333 \\
\hline Mass density, $\rho$ & $2000 \mathrm{~kg} / \mathrm{m}^{3}$ \\
\hline P-wave speed, $c_{p}$ & $240 \mathrm{~m} / \mathrm{s}$ \\
\hline S-wave speed, $c_{s}$ & $120 \mathrm{~m} / \mathrm{s}$ \\
\hline
\end{tabular}

In the hemispherical mesh considered here the infinite elements are expected to give good absorption for circular propagating wavefronts that impinge perpendicular to the boundary [37], [38], as indicated in Fig. 1(b). However, this has the disadvantage that the mesh is more complex. Moreover, for a moving load problem the load is not concentrated at the centre but 
moves across the upper surface of the ground. For these reasons a cuboid mesh is also considered, as described in the next section.

\subsection{Cuboid ground model}

Modelling the ground as a cuboid, as shown in Fig. 2, allows a regular mesh to be used which is much simpler to generate than for the hemispherical mesh. Again, use is made of symmetry in the $x-y$ plane. Two different types of model are considered. In the first, a fixed boundary is used on the bottom and on each side, as shown in Fig. 2(a), whereas, in the second, infinite elements are placed on the face opposite the symmetry plane, as shown in Fig. 2(b). The infinite elements are not considered at the front and back surfaces as smaller effects are expected from reflections from this direction; this will be discussed further in Section 5.1.2 below. The models are $30 \mathrm{~m}$ deep. Two different widths, 20 and $40 \mathrm{~m}$, are considered for the model without infinite elements but only a $20 \mathrm{~m}$ wide finite domain is used for the case with

the infinite elements. Various lengths of model have been considered. In each case the mesh consists of 20-node quadratic brick elements (C3D20) and 12-node infinite elements (CIN3D12R). The latter are used for compatibility with the quadratic elements in the finite element domain. Two different sets of ground parameters are again considered with the properties listed in Tables 1 and 2.

A constant element size of $0.5 \mathrm{~m}$ is used in the axial $(x)$ direction. In the $y$ and $z$ directions a graded mesh is used in which the element size is increased gradually from $0.5 \mathrm{~m}$ at the track, with a stretching factor of 1.2, as seen in Fig. 2. Thus, for example, at $30 \mathrm{~m}$ the element size is about $5 \mathrm{~m}$. The justification for this is that the influence of Rayleigh waves is limited to a depth of about one wavelength. Thus at about $2 \mathrm{~Hz}$, where the Rayleigh wavelength is equal to the depth of $30 \mathrm{~m}$, the element size of about $5 \mathrm{~m}$ is sufficient; at higher frequencies the wave penetrates less far and so smaller elements are only required to a shallower depth. The use of such a graded mesh avoids introducing discontinuities in the element size. At the ground surface, the wavenumber component in the axial direction is much greater than in the lateral direction so the resolution in the lateral direction is less important. 

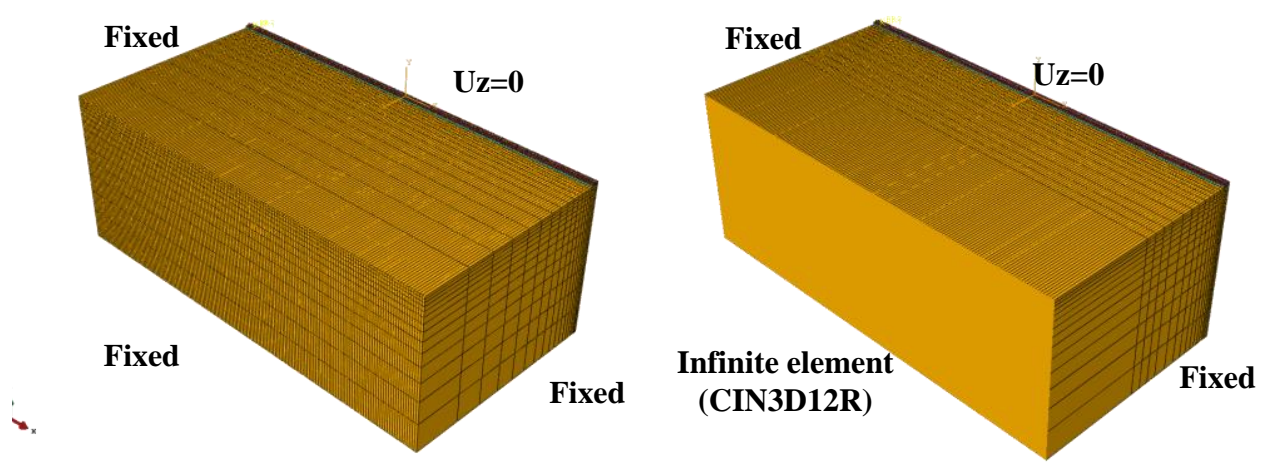

Figure 2. Cuboid model; (a) fixed boundary; (b) fixed boundary with infinite elements

\subsection{Track model}

The track consists of UIC60 rail supported on railpads, sleepers and a layer of ballast, as shown in Fig. 3. A single rail is included as a symmetry plane is assumed along the track centreline. Although the model is based on a UIC60 rail section, this is represented by an equivalent rectangular cross-section, $0.035 \times 0.218 \mathrm{~m}^{2}$, with the same mass and vertical bending stiffness as the UIC60 section. The railpads and sleepers are represented by equivalent continuous models. For the rail, railpad and sleeper, 20-node fully integrated quadratic brick elements are used. As for the ground, the element length in the axial direction is $0.25 \mathrm{~m}$ for hemispherical mesh and $0.5 \mathrm{~m}$ for cuboid mesh. The fully integrated quadratic elements are capable of representing the bending behaviour of beams reliably. For the railpad, the elements are only required to give the correct vertical stiffness. The behaviour of both rails and railpads has been checked in a model of a rail on a Winkler foundation and shown to give reliable predictions up to $300 \mathrm{~Hz}$.

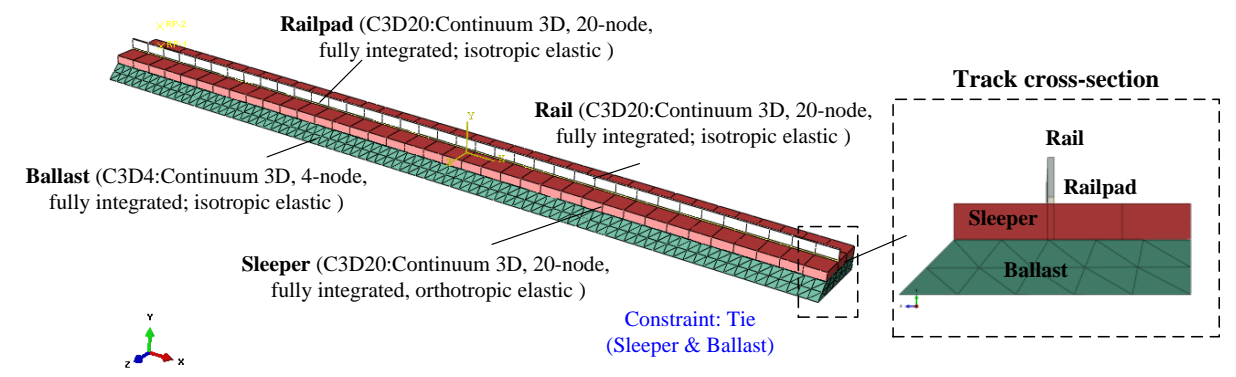

(a) 


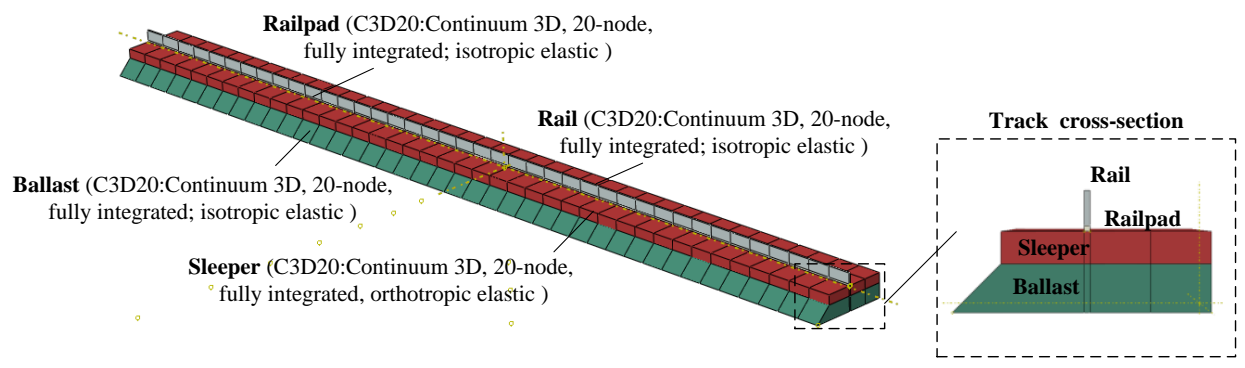

(b)

Figure 3. Three-dimensional ballasted track model; (a) for hemispherical model; (b) for cuboid model

For use with the hemispherical ground model, four-node tetrahedral elements are used for the ballast for compatibility with the ground surface, as shown in Fig. 3(a). Tie constraints are used between the sleeper and ballast as this provides a simple way to bond the surfaces together without requiring the meshes to match. This constraint prevents the slave nodes from separating or sliding relative to the master surface; therefore, there are no relative displacements between the two surfaces. However, for use with the cuboid ground model, 20node fully integrated brick elements are used for the ballast, as shown in Fig. 3(b) and there is no need for tie constraints as the meshes are compatible.

The parameters used for the track are listed in Table 3. Homogeneous material properties are used for the whole track model except the sleepers. The sleepers are represented by an equivalent continuous layer along the axial direction, with the density and Young's modulus factored by the ratio of the sleeper width $(0.25 \mathrm{~m})$ to the spacing $(0.6 \mathrm{~m})$. The sleepers are modelled using a transversely isotropic material so that they have no bending stiffness in the axial direction.

Table 3. Track properties

\begin{tabular}{|c|c|c|}
\hline Parameter & Value & Units \\
\hline Rail distance from symmetry plane & 0.75 & $\mathrm{~m}$ \\
\hline Rail mass & 60 & $\mathrm{~kg} / \mathrm{m}$ \\
\hline Rail bending stiffness & $6.4 \times 10^{6}$ & $\mathrm{Nm}^{2}$ \\
\hline Rail Poisson's ratio & 0.3 & \\
\hline Rail equivalent cross section & $0.035 \times 0.218$ & $\mathrm{~m}^{2}$ \\
\hline Rail pad stiffness per unit length & $5 \times 10^{8}$ & $\mathrm{~N} / \mathrm{m}^{2}$ \\
\hline Half sleeper length & 1.3 & $\mathrm{~m}$ \\
\hline Sleeper height & 0.2 & $\mathrm{~m}$ \\
\hline Sleeper equivalent Young's modulus $\left(E_{y}, E_{z}\right)$ & $1.25 \times 10^{10}$ & $\mathrm{~kg} / \mathrm{m}^{3}$ \\
\hline
\end{tabular}




\begin{tabular}{|c|c|c|}
\hline Sleeper equivalent Young's modulus $\left(E_{x}\right)$ & 0 & $\mathrm{~N} / \mathrm{m}^{2}$ \\
\hline Sleeper Poisson's ratio & 0.15 & \\
\hline Ballast depth (below sleeper) & 0.3 & $\mathrm{~m}$ \\
\hline Half ballast width at top & 1.3 & $\mathrm{~m}$ \\
\hline Half ballast width at bottom & 1.6 & $\mathrm{~m}$ \\
\hline Ballast Young's modulus & $4.8 \times 10^{8}$ & $\mathrm{~N} / \mathrm{m}^{2}$ \\
\hline Ballast density & 2000 & $\mathrm{~kg} / \mathrm{m}^{3}$ \\
\hline Ballast Poisson's ratio & $1 / 3$ & \\
\hline
\end{tabular}

\subsection{Wavenumber finite element and boundary element method}

The wavenumber FE/BE method is a so-called 2.5D approach which is based on the assumption that the geometry in the longitudinal direction is invariant [21]. This has been implemented in software known as WANDS [52]. This has been used here to obtain solutions for the steady-state response to a moving load and to a static harmonic load for comparison with the FE models. The cross-section of the track/ground model used is shown in Fig. 4. The rail is modelled as an Euler-Bernoulli beam, whereas solid finite elements are used to model the railpads, sleepers and ballast and boundary elements are used to model the unbounded homogeneous soil. The results are obtained in the wavenumber domain by solving for the displacement at each frequency $\omega$ and wavenumber $\beta$. The results in the spatial domain can be recovered using an inverse Fourier transform with respect to the wavenumber

$$
\hat{u}(x, y, z, \omega)=\frac{1}{2 \pi} \sum_{-\beta_{\max }}^{\beta_{\max }} \tilde{u}(\beta, y, z, \omega) e^{i \beta x} \Delta \beta
$$

where $\hat{u}$ and $\tilde{u}$ are the displacement functions in space and wavenumber domain, respectively. $\Delta \beta$ is the wavenumber spacing (or resolution), $\beta_{\max }$ is the maximum wavenumber. These two parameters need to be chosen carefully to obtain reliable results. The resolution depends on the chosen wavenumber which has to be fine enough to capture the peaks in the integrand. However, the maximum wavenumber should be large enough to cover all the relevant waves at the frequencies of interest. Here $\beta_{\max }$ is set to $6.42 \mathrm{rad} / \mathrm{m}$ and $\Delta \beta$ is chosen to give 1024 wavenumbers over the range from $-\beta_{\max }$ to $\beta_{\max }$.

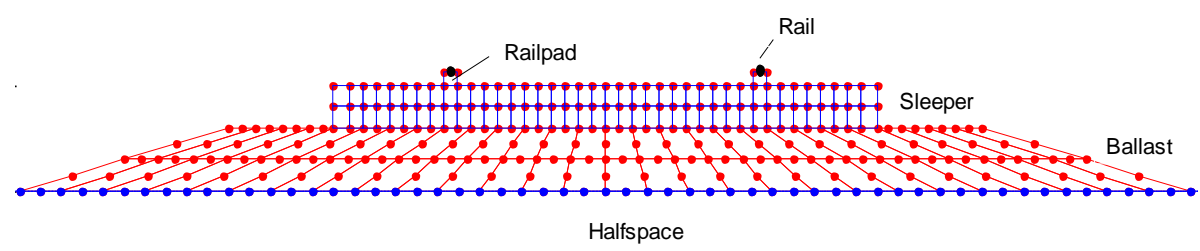

Figure 4. Cross-section of track and ground model in wavenumber FE/BE method 


\section{Material damping model}

\subsection{Rayleigh damping}

The damping of the ground is often expressed in terms of a constant loss factor, e.g. [21], [24], as this corresponds well to field measurements. Such a damping model is usually called structural damping in which the damping is introduced as a complex valued shear modulus (and Young's modulus) leading to complex wave propagation velocities [43]. However, in the time domain, such a model leads to non-causal response. Therefore, a viscous damping model, based on Rayleigh damping, is used here for the calculations with the FE model. The Rayleigh damping is based on two parameters $\alpha$ and $\beta$, which allow the damping matrix $\mathbf{C}$ to be determined from the mass and stiffness matrices, $\mathbf{M}$ and $\mathbf{K}$ :

$$
\mathbf{C}=\alpha \mathbf{M}+\beta \mathbf{K}
$$

This allows the equivalent loss factor $\eta$ or damping ratio $\xi$ to be obtained as a function of frequency as

$$
\frac{\eta}{2}=\xi=\frac{\alpha}{2 \omega}+\frac{\beta \omega}{2}
$$

where $\omega$ is the circular frequency at which the loss factor $\eta$ applies. In order to compare this damping model with the one for a constant loss factor, they can be set equal to one another at a single frequency, or possibly two frequencies. In general these frequencies are usually chosen to correspond to a resonance frequency of the system, due to the importance of the damping at resonances. However, in the present case of a moving load applied on a halfspace the results do not exhibit resonance phenomena and the choice of frequency is somewhat arbitrary.

A stiffness-proportional Rayleigh damping, equivalent to a Kelvin-Voigt damping, can be obtained by setting $\alpha$ equal to zero [41], [42]. Conversely, mass-proportional Rayleigh damping can be obtained by setting $\beta$ equal to zero [43]. A combined Rayleigh damping can be obtained by fitting the damping ratio to that measured at the site, as adopted by Hall [44].

Here, a constant loss factor of 0.05 is assumed in the wavenumber FE/BE model. Five different levels of Rayleigh damping are used: two with stiffness-proportional damping, two with mass-proportional damping and one combined case. These are based on fitting to a loss factor of 0.05 at either $12.5 \mathrm{~Hz}$ or $3 \mathrm{~Hz}$, as shown in Fig. 5(a). 
For a layered ground, when the travelling load speed is higher than the Rayleigh wave speed in the upper layer, an oscillation can be found behind the load [16]. The frequency of this oscillation can be identified approximately from the results of a static harmonic load in the frequency domain, discussed in Section 4.2 below. For the case of the layered half-space considered here, this oscillation is found at about $10 \mathrm{~Hz}$ and this is used as the dominant frequency at which to calculate the value for the viscous damping. Three different combinations of $\alpha$ and $\beta$ are used here for the layered half-space model, as shown in Fig. 5(b).

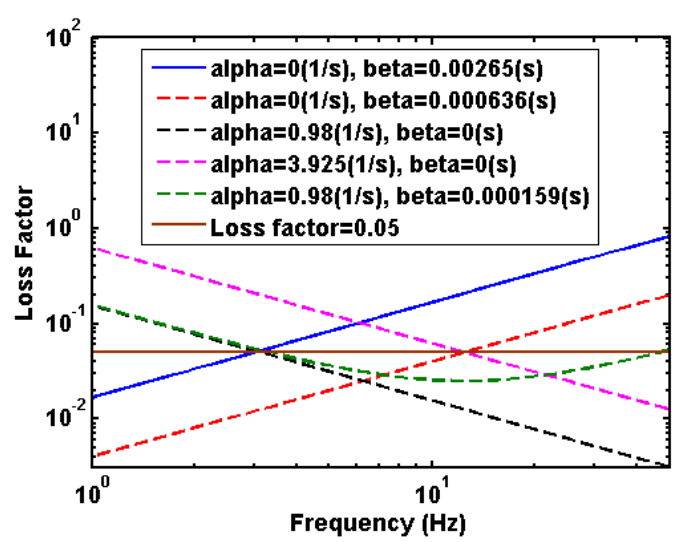

(a)

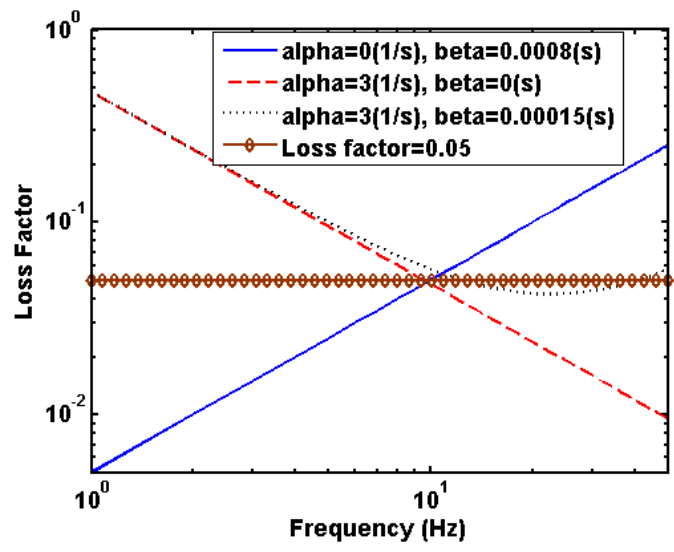

(b)

Figure 5. Equivalent loss factor (a) for half-space ground; (b) for layered half-space ground.

\subsection{Decay with distance for different damping models}

For a plane harmonic wave at circular frequency $\omega$ propagating in an elastic medium at a constant wave speed $c$, the wavenumber $k$ is given by $k=\omega / c$. In the presence of damping with a damping ratio $\xi$ the wavenumber becomes complex with the form $\bar{k}=k(1-i \xi)$. The imaginary part is related to the decay with distance which can be expressed in $\mathrm{dB} / \mathrm{m}$ as

$$
D=-20 \log _{10}\left(\left|e^{i \bar{k}}\right|\right)=-8.69 \operatorname{Im}(\bar{k})=8.69 k \xi
$$

For the case of a constant loss factor $\eta=2 \xi$, the decay with distance is found to be $D=4.34 \omega \eta / c$ which increases in proportion to the frequency. For example, for $\eta=0.05$ and $c=57 \mathrm{~m} / \mathrm{s}$, corresponding to the Rayleigh wave speed used here, the decay with distance is $0.02 \mathrm{~dB} / \mathrm{m}$ at $1 \mathrm{~Hz}$ rising to $1.2 \mathrm{~dB} / \mathrm{m}$ at $50 \mathrm{~Hz}$.

From Eq. (8), the decay with distance for stiffness-proportional damping is proportional to the square of the frequency, $D=4.34 \omega^{2} \beta / c$. So, for example, for $\beta=0.00265$ s (equivalent to $\eta=0.05$ at $3 \mathrm{~Hz}$ ) the decay with distance is $0.008 \mathrm{~dB} / \mathrm{m}$ at $1 \mathrm{~Hz}$ rising to $49 \mathrm{~dB} / \mathrm{m}$ at 50 
Hz. Conversely for mass-proportional damping $D$ is independent of frequency, $D=4.34 \alpha / c$. Thus for $\alpha=0.98 \mathrm{~s}^{-1}, D$ is $0.075 \mathrm{~dB} / \mathrm{m}$ for all frequencies. As a result it can be expected that mass-proportional damping will be equally effective at suppressing reflections from the domain boundaries at all frequencies, whereas stiffness-proportional damping will be ineffective at low frequencies.

\section{Harmonic analysis}

Before considering a moving load, a static harmonic load is applied at the centre of each ground model to investigate the influence of the boundaries in each case. Furthermore, the effect of different damping models is compared.

\subsection{Homogeneous half-space ground}

A unit harmonic load is applied on the rail at the midpoint of each homogeneous half-space model. Fig. 6(a) shows the point receptance (displacement for a unit force as a function of frequency) for the hemispherical models with three different radii including infinite elements. The results from the wavenumber FE/BE model are shown for comparison. 50 logarithmic frequency spaced points are used from $1 \mathrm{~Hz}$ to $50 \mathrm{~Hz}$. The models with $10 \mathrm{~m}$ and $20 \mathrm{~m}$ radius exhibit fluctuations in the receptance due to the effect of the boundaries, whereas the $40 \mathrm{~m}$ radius model shows a smoother receptance due to better absorption efficiency. This will therefore be used in subsequent analyses. Fig. 6(b) shows the receptance from the $40 \mathrm{~m}$ radius model for different load positions along the rail. These results are mostly similar although for a load position of $-35 \mathrm{~m}$ some fluctuations can be seen in the receptance, up to the equivalent of $1 \mathrm{~dB}$. At low frequency the results from the wavenumber FE/BE model are slightly higher than those from the FE model, which is due to different mesh density. Although better agreement can be obtained when smaller elements are used for the FE model, it is much more expensive and only gives a small improvement compared with the mesh used here. 


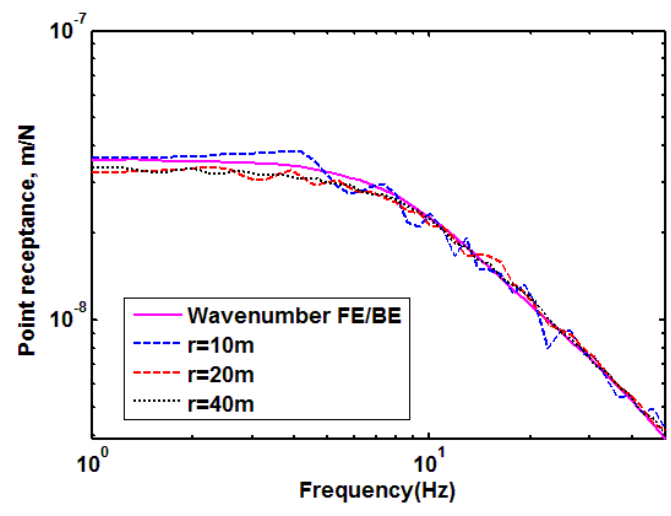

(a)

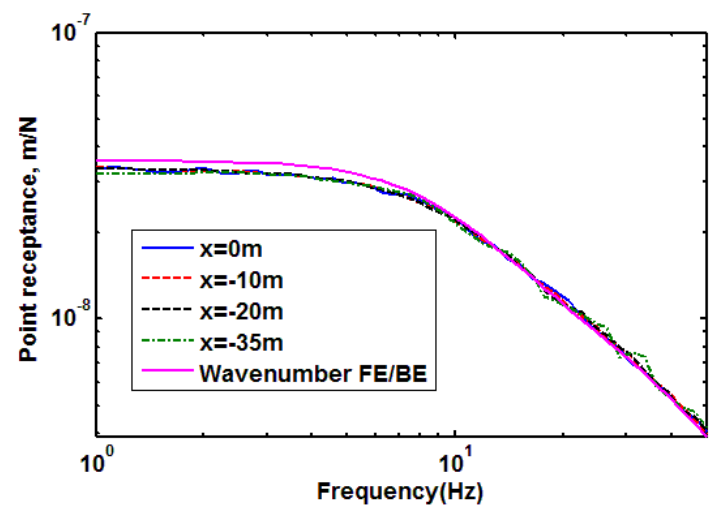

(b)

Figure 6. Point receptance on the rail for homogeneous half-space ground $\left(\alpha=0.98 \mathrm{~s}^{-1}, \beta=\right.$ $0.000159 \mathrm{~s}$ ); (a) by using three different hemispherical models ; (b) when load applied at different locations for $40 \mathrm{~m}$ radius model

In Fig. 7 the results from this hemispherical model with infinite elements are compared with the results from the wavenumber FE/BE model and from two cuboid FE models. The cuboid model without infinite elements has dimensions $40 \times 80 \times 30 \mathrm{~m}$ and that with infinite elements along the sides has dimensions $20 \times 80 \times 30 \mathrm{~m}$ for the finite element domain. Thus, as well as their dimensions, there are differences in the boundary conditions of these models. The five graphs show the results for the five different representations of viscous damping, as shown in Fig. 5(a).

The results from the hemispherical model show very good agreement with those from the wavenumber FE/BE model and only small differences are found when using different damping values as the infinite elements control the reflections. In contrast, the results from the two cuboid models show significant variation depending on the value of damping used. Even though the results from the cuboid model with infinite elements show less fluctuation than those without the infinite elements, some small oscillations still can be found. The cuboid model with infinite elements will not be considered further as, although it gives improved results, it is much less efficient than the cuboid model without the infinite elements. 


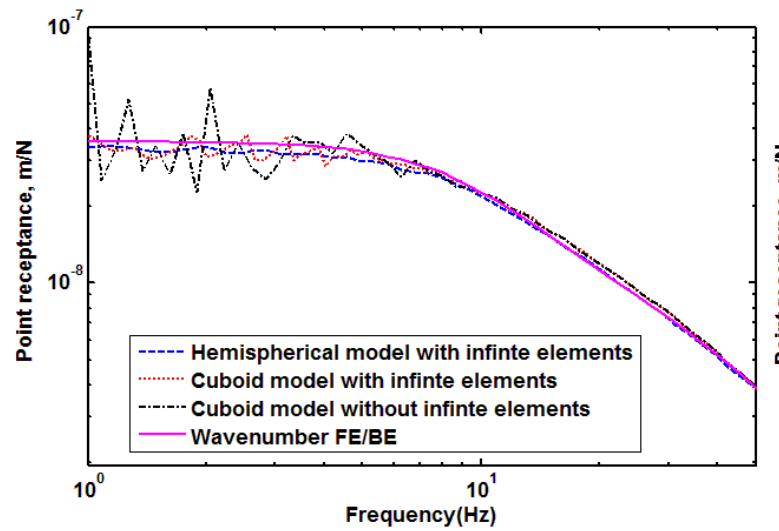

(a)

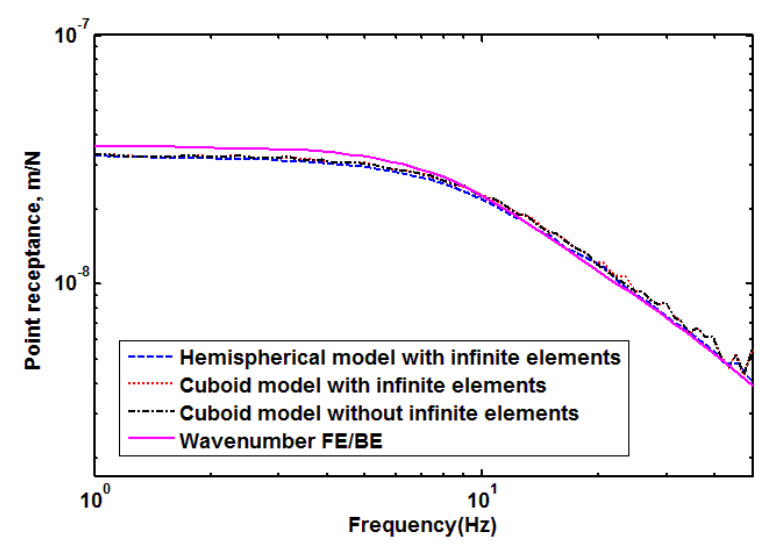

(c)

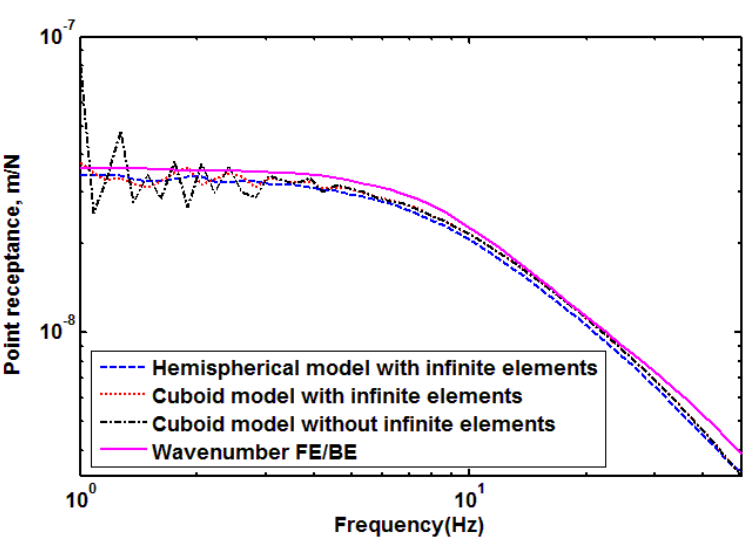

(b)

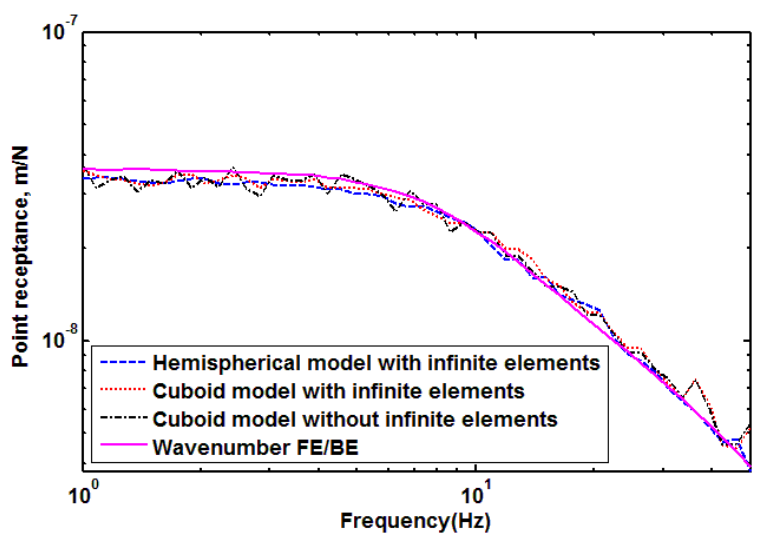

(d)

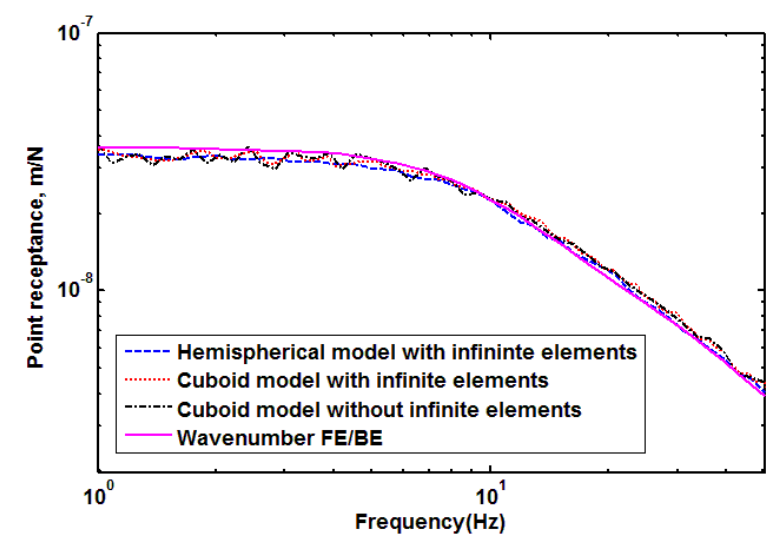

(e)

Figure 7. Point receptance on the rail for homogeneous half-space; (a) $\alpha=0, \beta=0.000636 \mathrm{~s}$; (b) $\alpha=0, \beta=0.00265 \mathrm{~s}$; (c) $\alpha=3.925 \mathrm{~s}^{-1}, \beta=0$; (d) $\alpha=0.98 \mathrm{~s}^{-1}, \beta=0$; (e) $\alpha=0.98 \mathrm{~s}^{-1}, \beta=$

$$
0.000159 \mathrm{~s}
$$

In Fig. 7(a) (b) stiffness-proportional damping is used. Here, for the cuboid model without infinite elements, severe oscillations $( \pm 5 \mathrm{~dB})$ are found at low frequencies due to reflections from the boundaries, as the equivalent loss factor is too small, see Fig. 5(a). Increasing $\beta$ 
reduces this effect slightly, while the results become smoother at higher frequencies. Fig. 7(c) (d) shows results for mass-proportional damping, in which $\beta$ is assumed to be zero. Here the oscillations at low frequency are much reduced and they become similar at all frequencies. Very good agreement can be seen in Fig. 7(c) whereas small oscillations $( \pm 1 \mathrm{~dB})$ can still be found in Fig. 7(d). The value of damping used in Fig. 7(d) can be considered just sufficient as a reduction of $6 \mathrm{~dB}$ is expected after $80 \mathrm{~m}$ (i.e. the distance to the boundary and back), see Section 3.2. In Fig. 7(e) the combined Rayleigh damping, $\alpha=0.98 \mathrm{~s}^{-1}$ and $\beta=0.000159 \mathrm{~s}$, gives good results across the whole frequency range with only a small oscillation (equivalent to less than $1 \mathrm{~dB}$ ) at low frequency. This is therefore used for the moving load example in Section 5.

\subsection{Homogeneous layered half-space ground}

For the layered half-space, the receptance due to a harmonic load applied at the centre of the track is shown in Fig. 8. Unlike the homogeneous half-space ground, a clear peak can be seen at around $10 \mathrm{~Hz}$. Compared with the wavenumber FE/BE model, the result based on the combined stiffness- and mass-proportional damping gives the best agreement and so this will be used for the moving load calculations.

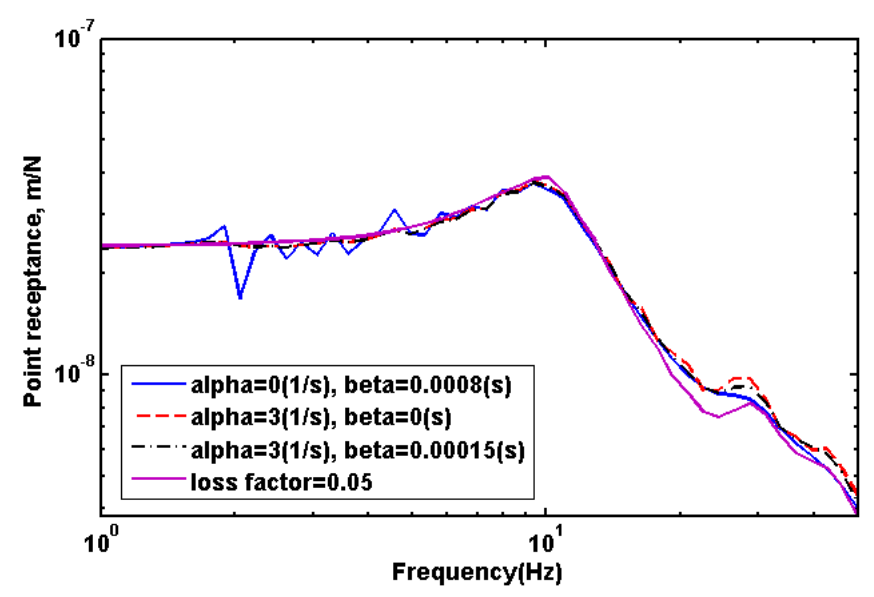

Figure 8. Receptance of layered half-space. Comparison of wavenumber FE/BE model (loss factor 0.05) with cuboid FE model with three different combinations of damping parameters

\section{Moving load analysis}

To investigate the effect of load speed on the response, a moving $1 \mathrm{~N}$ load is applied with constant speed on the different track/ground models. . 


\subsection{Homogeneous half-space ground with hemispherical mesh}

Initially the half-space ground is considered with a hemispherical FE mesh bounded by infinite elements. Three different sizes of model are compared, with radius $10 \mathrm{~m}, 20 \mathrm{~m}$ and $40 \mathrm{~m}$. The soil properties are as listed in Table 1 and the track properties as listed in Table 3. The damping model uses $\alpha=0.98 \mathrm{~s}^{-1}, \beta=0.000159 \mathrm{~s}$. The load is applied at a short distance away from one end of the rail (which is itself $1 \mathrm{~m}$ away from the boundary in hemispherical mesh) to avoid the boundary effect and the model is brought to equilibrium. Then it is moved with constant speed until it reaches a point again the same distance away from the other end.

Due to the use of infinite elements around the perimeter of the hemispherical mesh, the ground model is unconstrained statically. This is a consequence of the characteristics of the infinite elements, which resemble a dashpot (see Eq. (2)). Consequently it is found that, as the load traverses the track, the whole ground model tends to rotate and translate downwards, as indicated schematically in Fig. 9. However, this behaviour is artificial and can lead to misleading results, as discussed further in [53]. The displacement time histories at five different locations on the rail are shown in Fig. 10 for a load speed of $10 \mathrm{~m} / \mathrm{s}$ from the model with radius $10 \mathrm{~m}$. The load runs from $-8 \mathrm{~m}$ to $8 \mathrm{~m}$. Due to the unrealistic rigid body motion, the displacements at $x=-4 \mathrm{~m}$, and $x=-8 \mathrm{~m}$ continuously increase after the load has passed. The maximum downward displacement is larger at $x=4 \mathrm{~m}$ and $x=8 \mathrm{~m}$ due to the rotation of the ground model.

Fig. 11 compares results from hemispherical models with radius $10 \mathrm{~m}, 20 \mathrm{~m}$ and $40 \mathrm{~m}$. The maximum downward displacement of each node along the rail during the simulation is plotted when the load moves from $-8.5 \mathrm{~m}$ to $8.5 \mathrm{~m}$ in each case. The displacement increases significantly towards the boundary when the $10 \mathrm{~m}$ radius is used. However, this spurious phenomenon is considerably reduced when larger models are used due to the increase in inertia. Moreover, the effect can be minimised by plotting the displacement at the centre of the mesh, $x=0$. However, these effects are only avoided completely by using a mesh with a fixed boundary at the bottom. 


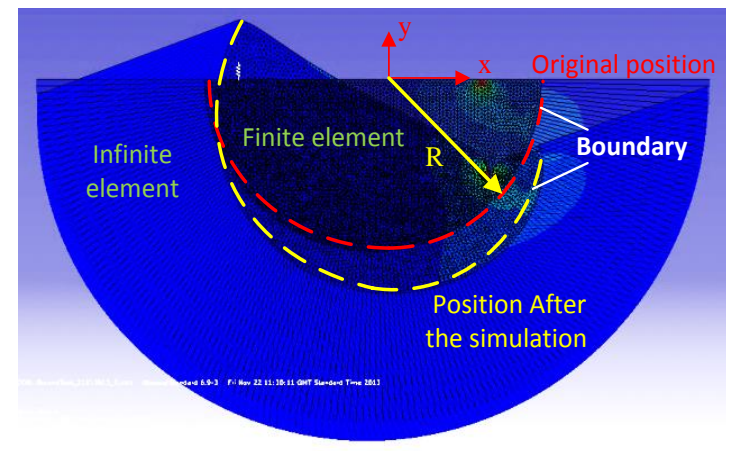

Figure 9. Schematic view of incorrect displacement occuring due to the motion of the moving load (exaggerated)

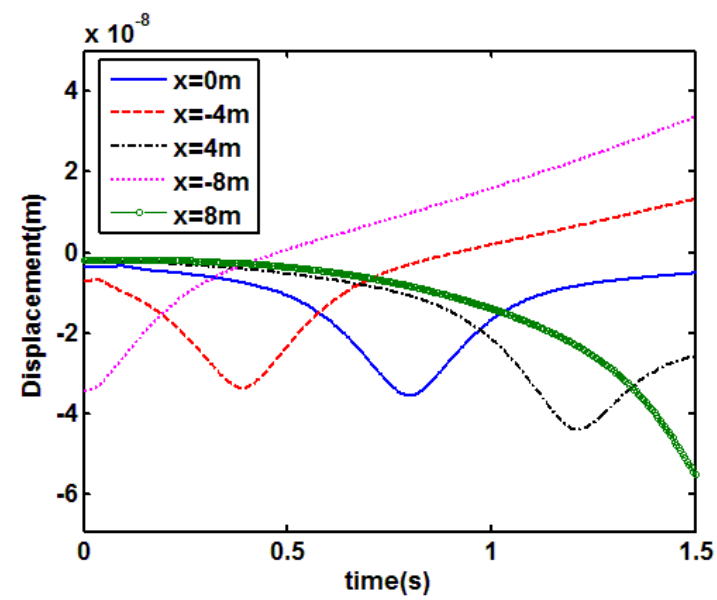

Figure 10. Rail displacement at five different locations when load speed is $10 \mathrm{~m} / \mathrm{s}$ (hemispherical model with radius $10 \mathrm{~m}$ )

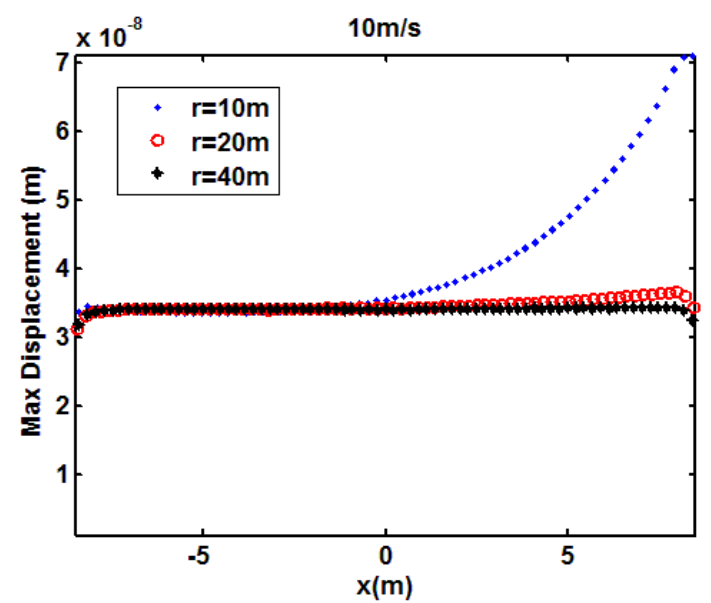

Figure 11. The maximum displacements at each position along the rail for a load speed 10 $\mathrm{m} / \mathrm{s}$ and three different sizes of hemispherical model

Fig. 12 shows the maximum downward deflection of the track at the centre during the passage of a unit load at various speeds. Results are shown for the three sizes of 
hemispherical mesh. These results are compared with the corresponding results from the wavenumber FE/BE model. The deflection increases as the speed increases until it reaches a maximum at $57 \mathrm{~m} / \mathrm{s}$, which is equal to the Rayleigh wave speed in the ground. The results from the FE model agree well with those from the wavenumber FE/BE model at lower speeds. However, significant differences can be seen when the load speed is close to the critical speed of $57 \mathrm{~m} / \mathrm{s}$. The maximum deflection increases as the size of the model is increased, but it does not reach the value found for the wavenumber FE/BE model, suggesting that the length of the FE mesh used is insufficient to achieve convergence.

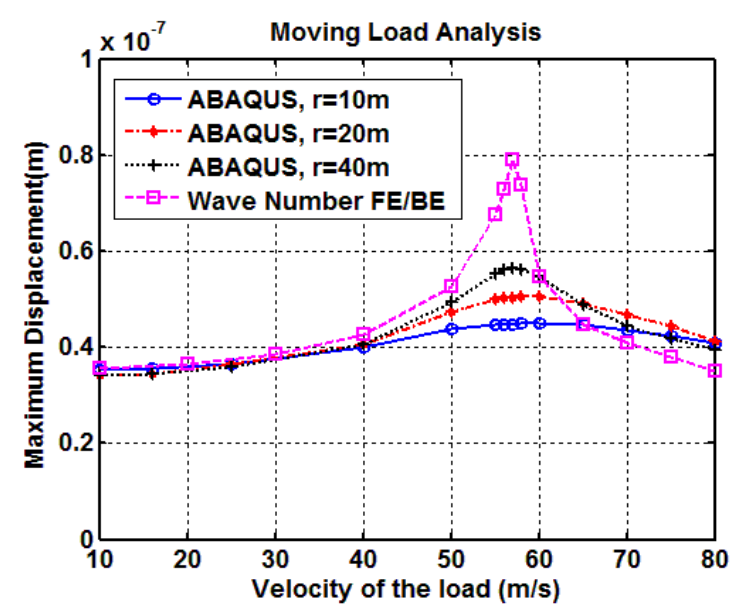

Figure 12. Maximum deflection of track during the passage of a unit load plotted as a function of speed for a homogeneous half-space ground modelled using hemispherical mesh with different radii

To investigate this further, Fig. 13 shows the evolution of the ground deformation for a load speed $57 \mathrm{~m} / \mathrm{s}$. These results are obtained using the $40 \mathrm{~m}$ radius hemispherical model at three different time steps, $0.4,0.7$ and $1.0 \mathrm{~s}$. The load is moving from right to left in these figures; on the left is a plan view and on the right a side view through the centre of the model. It can be seen that the maximum amplitude of the deformation becomes larger with increasing time. Furthermore, the angle between the deformed region and the mid plane increases during the simulation. This development of the wavefronts depends on the geometrical spreading of the waves and the propagation velocities of the different waves [44], [45]. It is therefore important that a sufficiently long model is used to achieve steady-state results. The evidence presented suggests that $40 \mathrm{~m}$ is not sufficient. Increasing the size of the hemispherical mesh further is inefficient as the depth must become larger as well as the length. The effect of mesh size will therefore be investigated further below using the cuboid mesh. 


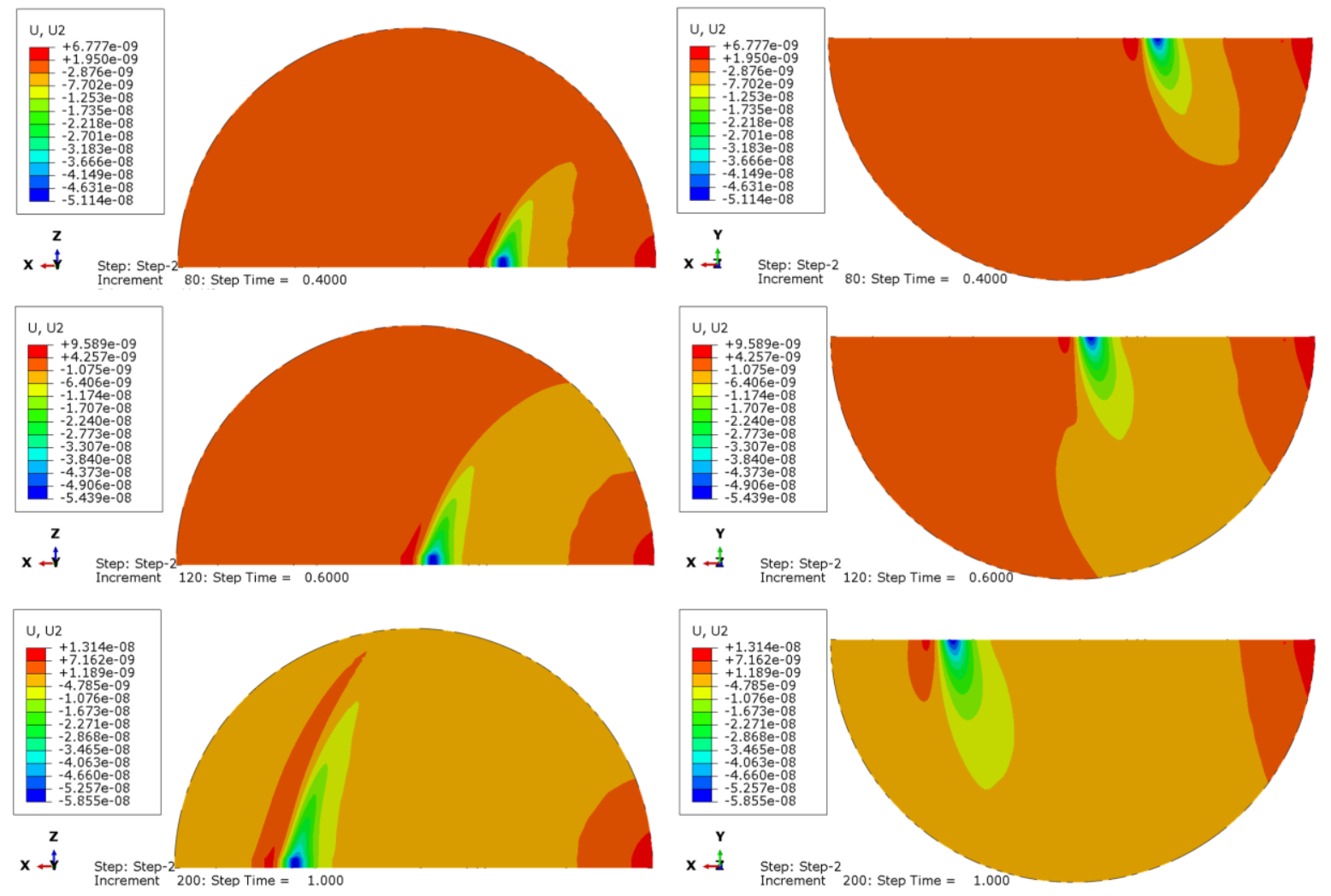

Figure 13. Evolution of the deformation under a moving load when load speed is $57 \mathrm{~m} / \mathrm{s}$ (left: top view; right: side view; upper: $0.4 \mathrm{~s}$; centre: $0.6 \mathrm{~s}$; lower $1.0 \mathrm{~s}$ )

\subsection{Cuboid mesh with 20 m width}

A $20 \mathrm{~m}$ wide cuboid model without infinite elements is used first with damping, $\alpha=0.98 \mathrm{~s}^{-1}$ $\beta=0.000159 \mathrm{~s}$ to investigate the effect of the fixed boundaries. The rail midpoint displacement is shown in Fig. 14 for two different speeds, $40 \mathrm{~m} / \mathrm{s}$ (lower than the critical speed) and $60 \mathrm{~m} / \mathrm{s}$ (higher than the critical speed). No reflection is found from the axial direction due to the fact that the traveling time is not sufficient for the reflected Rayleigh wave to come back to the observation point, which takes $4 \mathrm{~s}$. Furthermore, the reflection from the bottom of the mesh is negligible. This is because the Rayleigh waves are attenuated much faster in the vertical direction than along the surface [54]. Three specific times are indicated in the figure to identify the various reflections. The black dotted line (1) represents the time of arrival of the load and the blue dashed line (2) represents the time of arrival of a Rayleigh wave propagating from the start point to the observation point. Finally the red dash-dot line (3) represents the time of arrival of the reflection from the side boundary (see below). As shown in Fig. 14(a), no reflection is found from the boundary when the load speed is less than the critical speed. In this case the deflection remains localised close to the track and does 
not spread out towards the boundary. However, a small feature can be seen before the load arrives at the observation point. This can be identified as being caused by the Rayleigh wave propagating from the start point to the observation point. On the other hand, a clear reflection from the side boundary can be seen when the load speed is higher than the critical speed, as shown in Fig. 14(b).

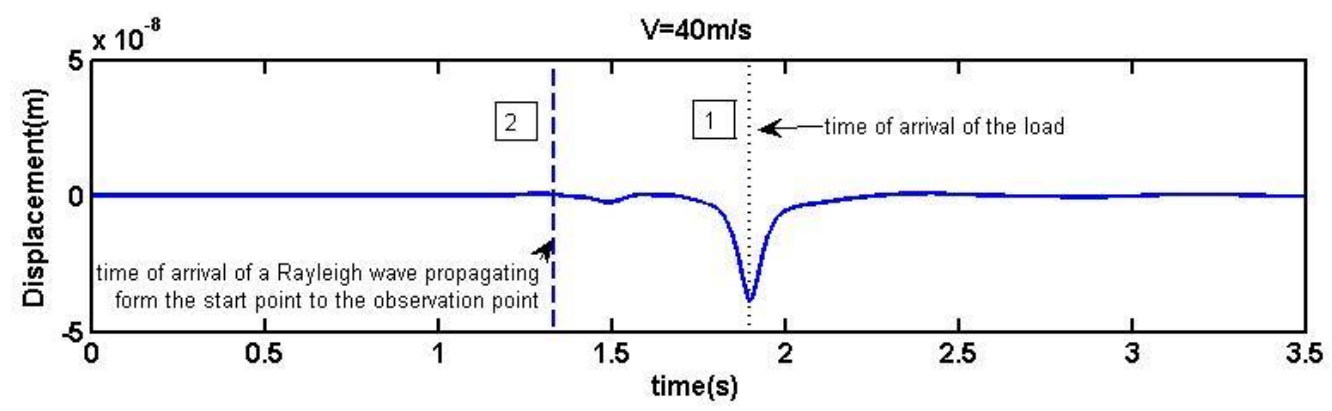

(a)

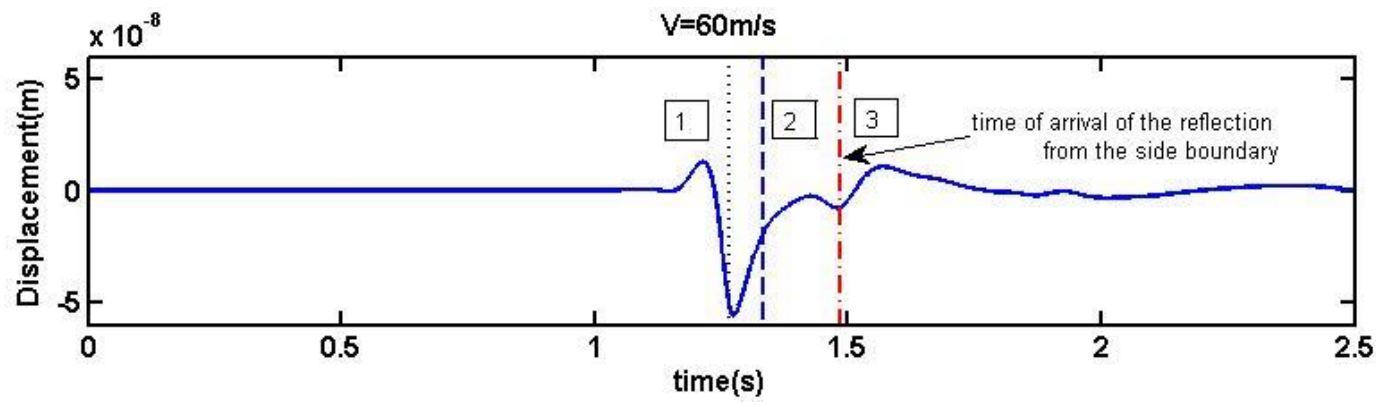

(b)

Figure 14. Rail midpoint displacement with different load speeds (a) V=40m/s; (b) $60 \mathrm{~m} / \mathrm{s}$

When the load travels faster than the Rayleigh wave speed, the wave propagates at a certain angle to the track towards the side boundary and is reflected back at the same angle, as shown in Fig. 15. Therefore, the time of arrival of the reflected wave can be found as

$$
t=t_{2}-t_{1}=\frac{2 W}{V \tan \theta}
$$

where $t_{1}$ is the time of arrival of the wave at the observation point, and $t_{2}$ is the time of arrival of the reflection at the observation point, as shown in Fig. 15. $V$ is the load of the speed, $\theta$ is the Mach angle, which can be calculated as

$$
\theta=\sin ^{-1} \frac{V_{R}}{V}
$$

and $W$ is the width of the model, which is $20 \mathrm{~m}$ in this case. 

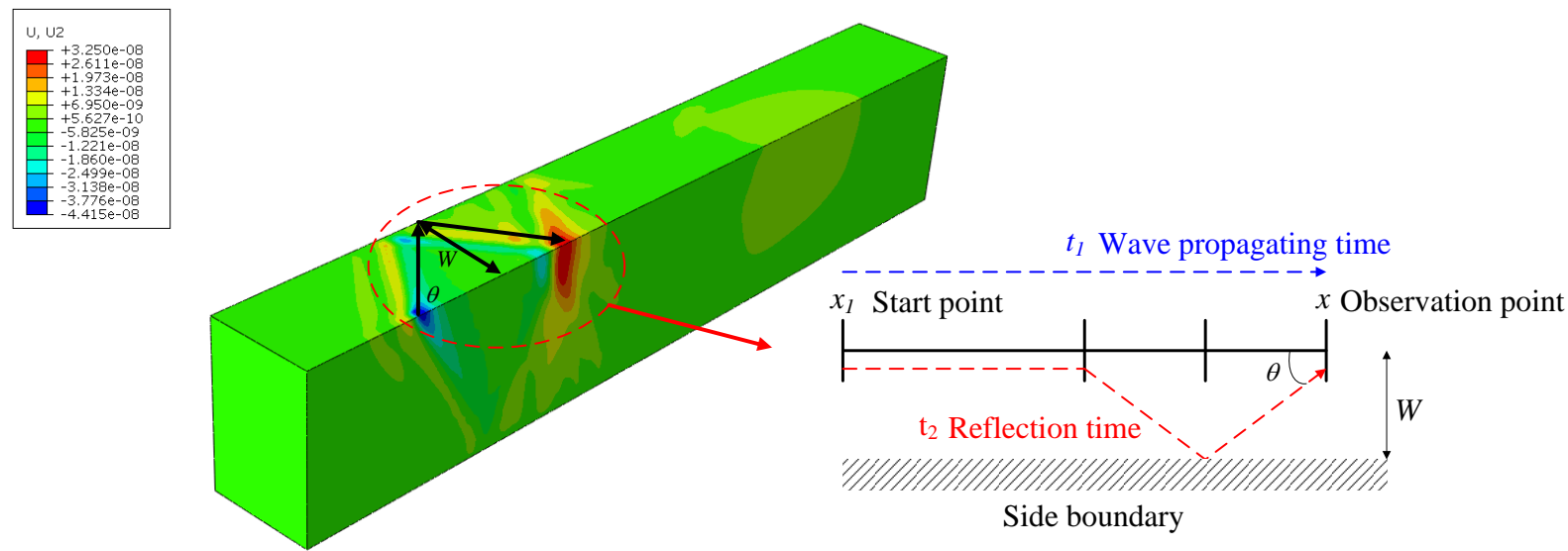

Figure 15. The route of the reflection wave propagating from the side boundary

\subsection{Cuboid mesh with $\mathbf{4 0}$ m width}

The results from a $40 \mathrm{~m}$ wide model are compared with those from a $20 \mathrm{~m}$ wide one in Fig. 16. No noticeable reflections are observed from the simulation when a $40 \mathrm{~m}$ wide model is used due to the increased attenuation of the waves to/from the boundary. Therefore, a $40 \mathrm{~m}$ wide model is better for modelling this moving load case. Also shown in this figure are results from the $20 \mathrm{~m}$ wide model with infinite elements. These results are an improvement on the $20 \mathrm{~m}$ wide model but still contain some evidence of a reflection from the boundary.

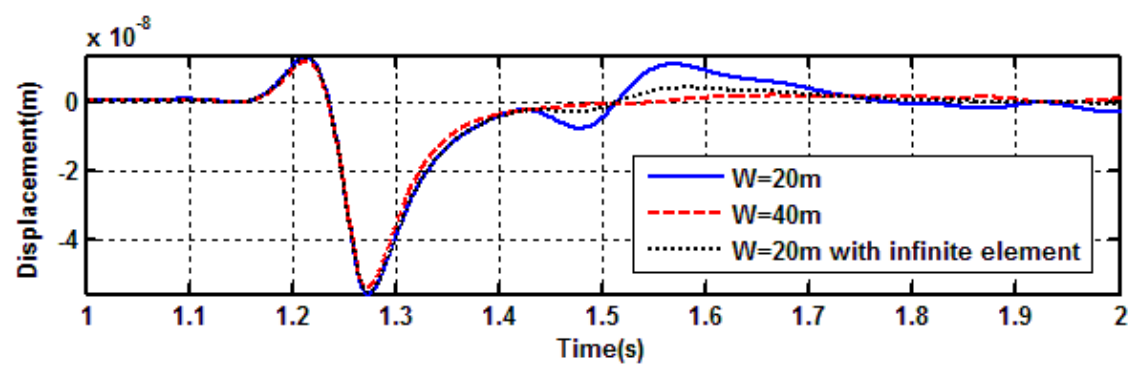

Figure 16. Rail displacement obtained by using different widths of the model when load speed is $60 \mathrm{~m} / \mathrm{s}$

It is thus shown that, provided that a suitable damping model is used, the spurious reflections from the sides of the model can be suppressed with a sufficiently wide model. On the other hand, if infinite elements are used the calculations are found to be considerably more costly even though the width of the model is much smaller. A comparison between the calculation times required for the moving load problem when using three different ground models is given in Table 4. These simulations were run in parallel using 16 processors on a supercomputer, iridis 4 , which has $2.6 \mathrm{GHz}$ processors with $4 \mathrm{~GB}$ of memory per processor. 
The $40 \mathrm{~m}$ wide model without infinite elements is thus preferred to the model with infinite elements.

Table 4. Calculation times and model sizes required for various models in ABAQUS

\begin{tabular}{|c|c|c|c|}
\hline $\mathrm{V}(\mathrm{m} / \mathrm{s})$ & $\begin{array}{c}\text { Cuboid 80x40x30 m } \\
\text { Time (hr) }\end{array}$ & $\begin{array}{c}\text { Cuboid 80x20x30 m with } \\
\text { infinite elementsTime (hr) }\end{array}$ & $\begin{array}{c}\text { Hemisphere with infinite } \\
\text { elements radius 40 } \mathrm{m} \\
\text { Time (hr) }\end{array}$ \\
\hline 40 & 11 & 27 & 18 \\
\hline 57 & 7.8 & 19 & 12.5 \\
\hline 80 & 5.5 & 13.5 & 9 \\
\hline dof & $1,181,472$ & $1,024,800$ & $1,4463,06$ \\
\hline
\end{tabular}

A cuboid model with dimensions $80 \times 40 \times 30 \mathrm{~m}$ and fixed boundaries (i.e. without infinite elements) is used to investigate the convergence of the solution. The maximum displacements of each node along the track during the simulation are presented in Fig. 17. The load is moving from left to right here. At low speed, after an initial transient, the deflection converges to a constant value until it approaches the right-hand end. The point at which the deflection has converged to the steady-state value is marked on the graph by an asterisk. This is determined by selecting a point at $30 \%$ of the distance (i.e. $24 \mathrm{~m}$ ) from the right-hand end and finding when the displacement converges to within $2 \%$ of this value. Also at $80 \mathrm{~m} / \mathrm{s}$ the deflection reaches the steady-state value within about $20 \mathrm{~m}$ from the start. However, at 57 $\mathrm{m} / \mathrm{s}$ the calculation does not converge when using this mesh. Instead, a longer mesh, $320 \times 40 \times 30 \mathrm{~m}$, has been used for this case. It can be seen in Fig. 17(c) that the calculation converges after $125 \mathrm{~m}$ at this speed.
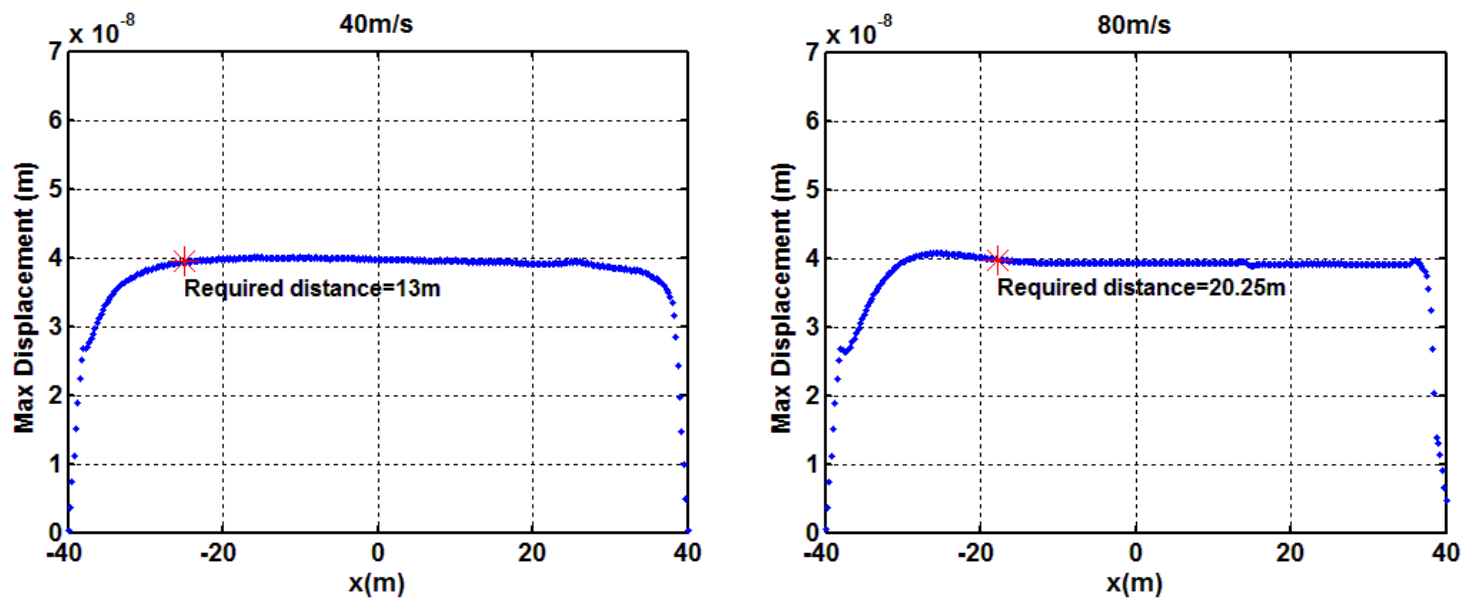
(a)

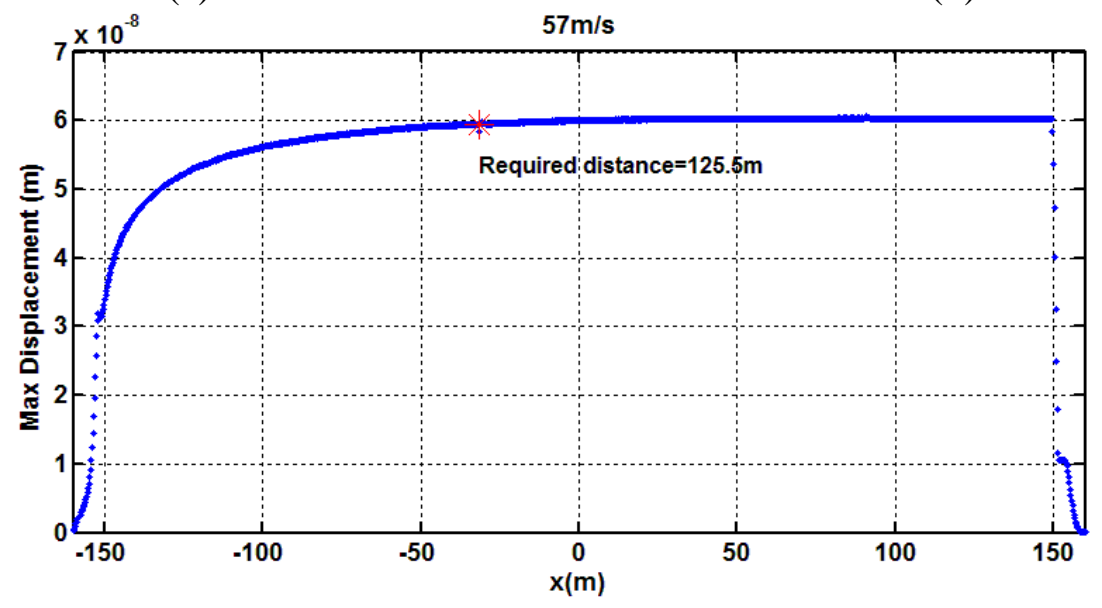

(c) (b)

c)

Figure 17. The maximum displacements along the rail; (a) V=40 m/s; (b) V=80 m/s; (c)

$$
\mathrm{V}=57 \mathrm{~m} / \mathrm{s}
$$

The distance required to converge to the steady-state is plotted in Fig. 18(a) for different load speeds. When the speed is close to the critical speed this distance is much longer, requiring the use of a very long model to reach the steady-state response. The effect of different damping levels is discussed in Section 5.4 below.

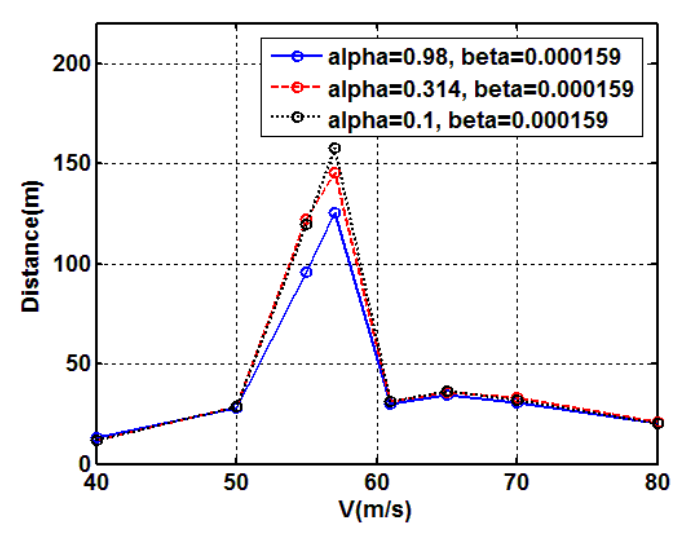

(a)

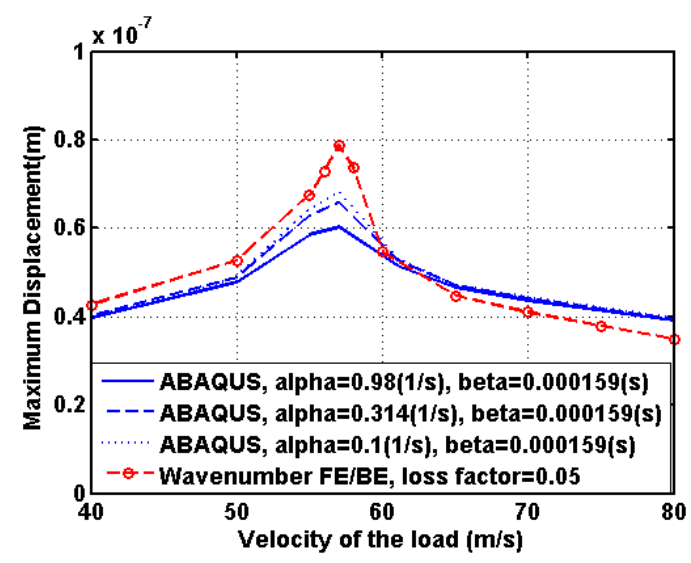

(b)

Figure 18. Assessment of critical speed for cuboid model of half-space ground with different damping; (a) Length of transient zone required for convergence to steady-state solution; (b) Maximum deflection of track during the passage of a unit load

Fig. 18(b) shows the maximum deflection of the track during the passage of a unit load as a function of load speed for the cuboid models. Better agreement is seen here with the wavenumber FE/BE model than was the case for the hemispherical model as shown in Fig. 
12. In Fig. 19 the results are shown in the space domain for three different speeds, $40 \mathrm{~m} / \mathrm{s}$, $57 \mathrm{~m} / \mathrm{s}$, and $80 \mathrm{~m} / \mathrm{s}$, after they have reached steady state. These are compared with the results from the wavenumber FE/BE model. Good agreement can be seen for the lower and higher speeds but the maximum amplitude at the critical speed is lower in the FE model than in the wavenumber FE/BE model. As will be discussed in the next section, this difference can be attributed to differences in the damping models.

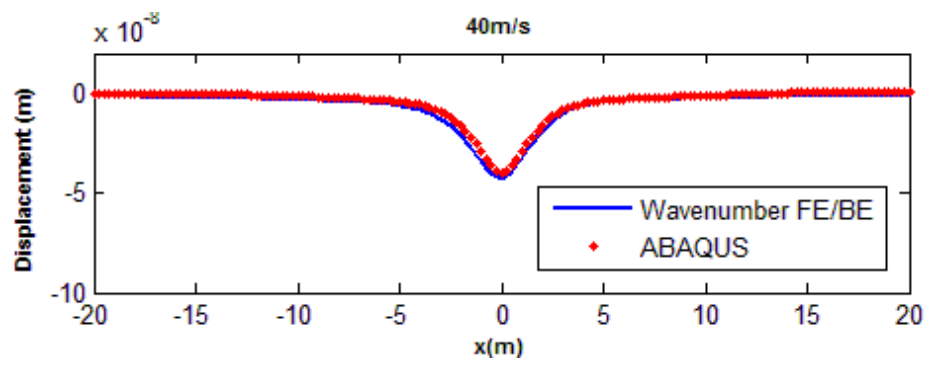

(a)

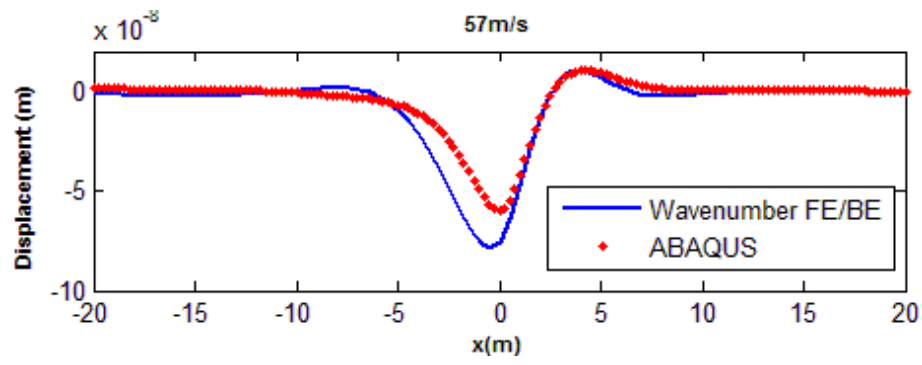

(b)

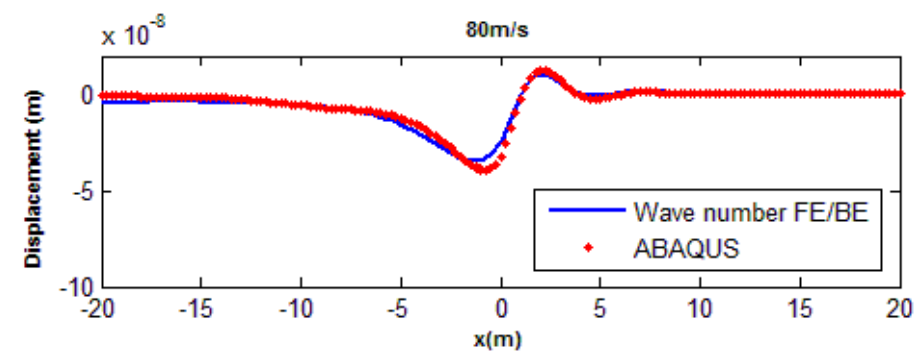

(c)

Figure 19. Displacement of the rail with different load speeds by using $\alpha=0.98 \mathrm{~s}^{-1}$, $\beta=0.000159 \mathrm{~s}$ in ABAQUS and 0.05 as loss factor for wavenumber FE/BE model; (a) V=40 $\mathrm{m} / \mathrm{s} ;$ (b) $\mathrm{V}=57 \mathrm{~m} / \mathrm{s}$; (c) $\mathrm{V}=80 \mathrm{~m} / \mathrm{s}$

\subsection{Damping analysis}

In the previous sections the Rayleigh damping was based on $\alpha=0.98 \mathrm{~s}^{-1}$ and $\beta=0.000159 \mathrm{~s}$. These values correspond to a loss factor of 0.05 at $3 \mathrm{~Hz}$, as shown in Fig. 5(a). In this section the effect of changing the damping description in the FE model is investigated. Three 
different values of $\alpha$ are used which are equivalent to $\eta=0.05$ at $3 \mathrm{~Hz}, 1 \mathrm{~Hz}$ and $0.3 \mathrm{~Hz}$, as shown in Fig. 20, whereas $\beta$ is kept fixed as $0.000159 \mathrm{~s}$.

The dependence of the amplitude on speed is shown in Fig. 18(b) for the various damping levels. As can be seen, the damping only influences the results close to the critical speed. The amplitude increases with lower values of $\alpha$ (or $\eta$ ). A smaller value of $\alpha$ is required to match the results from the wavenumber FE/BE model with loss factor 0.05. For comparison, the lengths required for convergence with these three different levels of damping are shown in Fig. 18(a). As shown, the required model size remains the same for all speeds except close to the critical speed, a longer model being required with smaller values of $\alpha$.

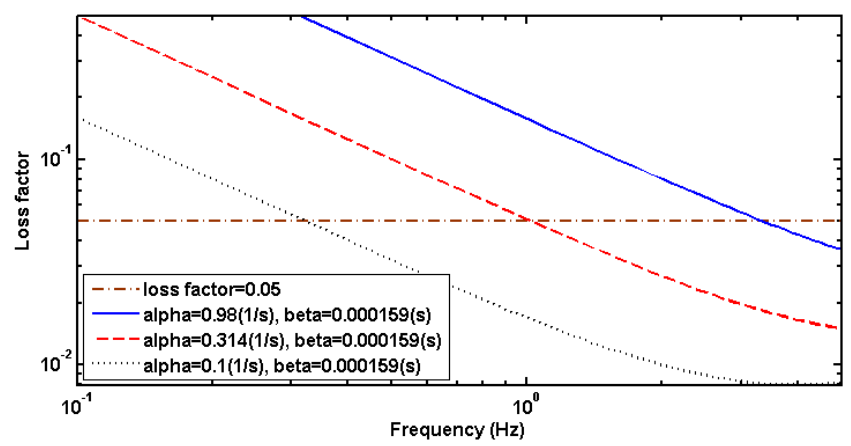

Figure 20. Equivalent loss factor by using three different viscous damping

\subsection{Layered half-space ground}

Results are presented in this section for a moving load on the layered half-space ground. The same $80 \times 40 \times 30 \mathrm{~m}$ cuboid mesh with fixed boundaries as used for the homogeneous halfspace is again used here with the same element sizes. The properties of the ground and track are given in Tables 2 and 3. The hemispherical model is not considered here due the problems identified earlier. Three different types of Rayleigh damping have been considered for the harmonic analysis, each based on $10 \mathrm{~Hz}$ as the dominant frequency, as mentioned in Section 2.4. Here, however, only the combined damping, $\alpha=3 \mathrm{~s}^{-1}, \beta=0.00015 \mathrm{~s}$ is considered for the moving load simulations.

The length required to reach steady state is shown in Fig. 21(a) for the layered ground. The required model size is much smaller than for the homogeneous half-space, especially at the critical speed. In Fig. 21(b) the maximum displacement is plotted against load speed. Good agreement can be seen compared with the results from the wavenumber FE/BE model. The results in the spatial domain at four different speeds are shown in Fig. 22; these results also 
agree well with the results from wavenumber FE/BE. The critical speed for the layered halfspace ground is identified as $82.5 \mathrm{~m} / \mathrm{s}$, which is higher than for the homogeneous half-space and higher than the Rayleigh wave speed in the soft soil layer.

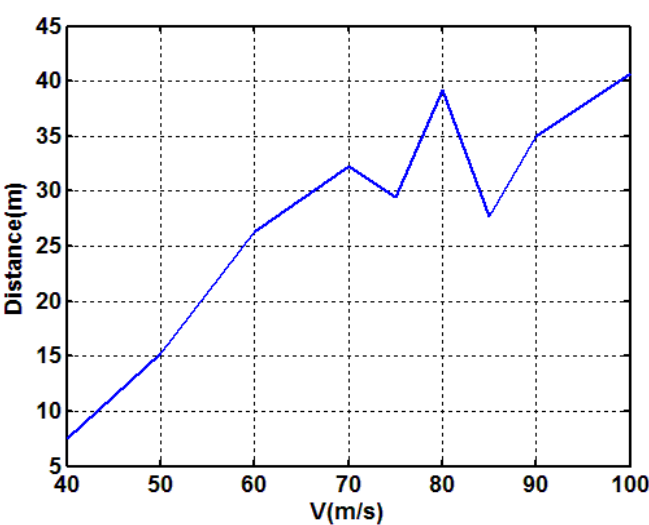

(a)

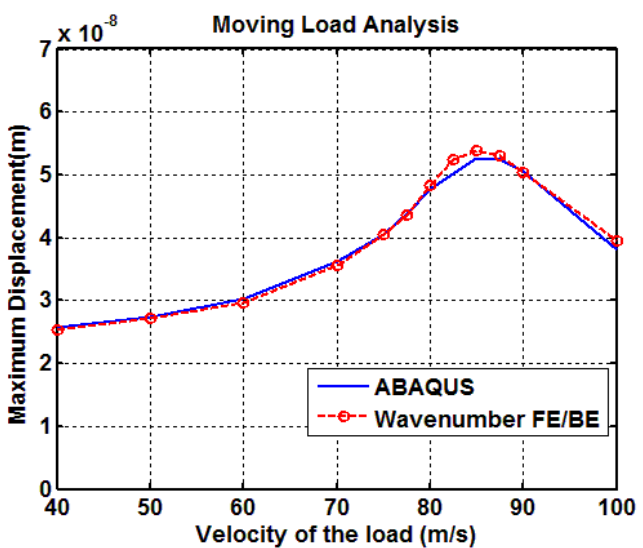

(b)

Figure 21. Results for layered half-space ground. (a) Length of transient zone required for convergence to steady-state solution for different load speeds; (b) Maximum deflection of track during the passage of a unit load plotted as a function of speed

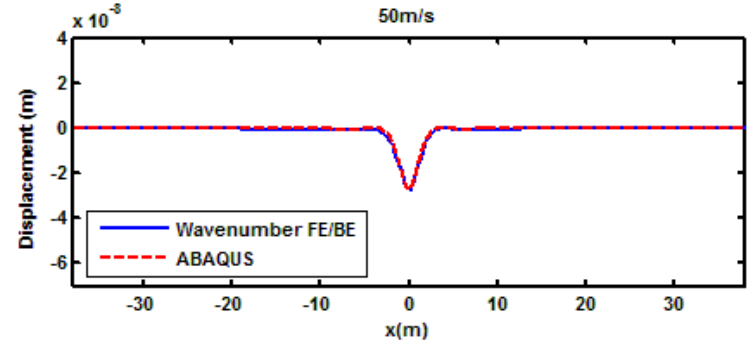

(a)

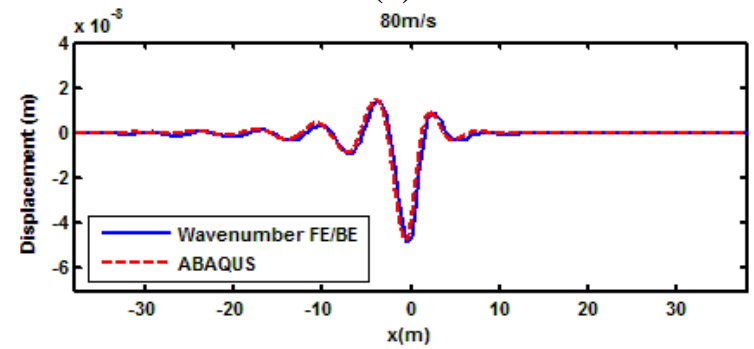

(b)

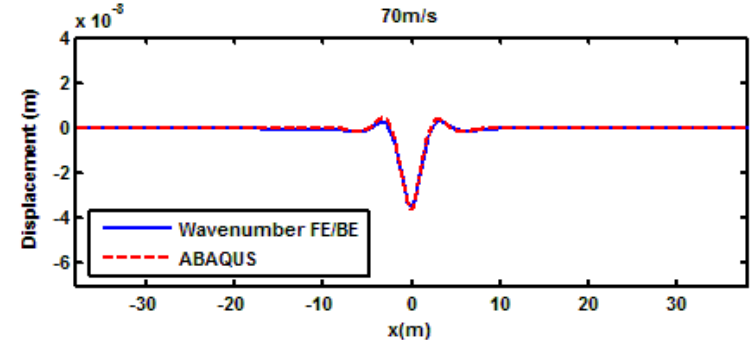

(b)

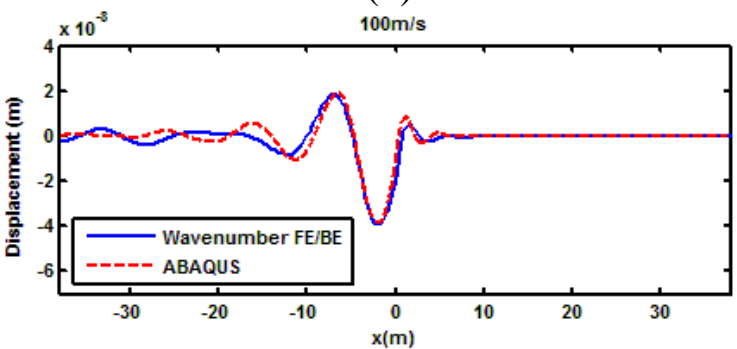

(d)

Figure 22. Comparison between the results from FE model and the results from wavenumber $\mathrm{FE} / \mathrm{BE}$ for layered half-space

\section{Conclusions}

A systematic investigation has been presented of the use of the time-domain finite element approach to represent a load moving on a railway track on a flexible ground. Two sets of 
ground parameters are considered: a homogeneous half-space with a shear wave velocity of $60 \mathrm{~m} / \mathrm{s}$ and a layered half-space in which this soil extends only to a depth of $2 \mathrm{~m}$, below which is a stiffer half-space. To prevent reflections from the boundaries of the finite domain two approaches are compared.

A $40 \mathrm{~m}$ radius hemispherical finite element mesh has been used first, with infinite elements around the perimeter to prevent reflections from the boundaries. This approach gives good results for a point harmonic load at the centre of the domain but some problems have been highlighted when it is used for moving load calculations. First, the infinite elements are less effective at reducing reflections when the load is close to the edge of the mesh, which is inevitable for a moving load. Second, the constant downward load applied to the track causes rigid-body deflections including rotation of the whole domain. It is difficult to eliminate this, although the problem is reduced as the mesh size increases due to the increased inertia of the ground model. Third, near the critical speed the hemispherical mesh used was found to be too short to allow the steady-state response to the moving load to be achieved. It is therefore desirable to have a larger domain but this becomes impractical with a hemispherical mesh as it increases in size in three directions.

An alternative approach has therefore been investigated based on a cuboid mesh. Suitable dimensions were found to be $30 \mathrm{~m}$ deep and $40 \mathrm{~m}$ wide (from the centreline). The required length depends on the proximity of the load speed to the critical speed. The base was fixed to prevent rigid-body motions and, rather than use infinite elements at the sides, these were also fixed. Provided that a suitable damping model is used the spurious reflections from the sides of the model can be suppressed with this width of model. On the other hand, if infinite elements are used the model does not need to be so wide but the calculations are found to be considerably more costly.

Different models of soil damping have been considered. A classical Kelvin-Voigt viscous damping model, in which the damping matrix is proportional to the stiffness matrix, suffers from spurious reflections at the domain boundaries at low frequencies. A mass-proportional damping model, on the other hand, is shown to give a decay with distance that is independent of frequency making it particularly suitable for this application. In order to approximate a constant loss factor, often found in field measurements of soil damping, a combination of mass- and stiffness-proportional damping can be used. In the case of the layered ground this 
damping model can be equated to a particular loss factor at the resonance frequency of the ground layer but with a homogeneous half-space there is no obvious dominant frequency at which to match the two damping models.

The length of model required to achieve steady state is found to increase considerably in the vicinity of the critical speed for a homogeneous half-space, up to $130 \mathrm{~m}$ in the present example, whereas for the layered ground a more modest length is sufficient even at the critical speed.

\section{Acknowledgements}

The work described has been supported by the EPSRC under the Programme Grant EP/H044949/1, 'Railway Track for the 21st Century'. All data published in this paper are openly available from the University of Southampton repository at doi:xxx/SOTON/xxx.

\section{References}

[1] L. Fryba, Vibration of Solids and Structures Under Moving Loads. London: Thomas Telford, 1999.

[2] A. S. J. Suiker, "The Mechanical Behaviour of Ballasted Railway Tracks," Phd thesis, TU Delft, The Netherlands, 2002.

[3] A. M. Kaynia, C. Madshus, and P. Zackrisson, "Ground vibration from high-speed trains: prediction and countermeasure," J. Geotech. Geoenvironmental Eng., vol. 126, no. 6, pp. 531-537, Jun. 2000.

[4] C. Madshus and A. M. Kaynia, "High-speed railway lines on soft ground: dynamic behaviour at critical train speed," J. Sound Vib., vol. 231, no. 3, pp. 689-701, 2000.

[5] X. Sheng, C. J. C. Jones, and D. J. Thompson, "A theoretical study on the influence of the track on train-induced ground vibration," J. Sound Vib., vol. 272, no. 3-5, pp. 909936, May 2004.

[6] J. T. Kenney, "Steady-state vibrations of beam on elastic foundation for moving load," J. Appl. Mech., vol. 76, pp. 359-364, 1954.

[7] S. Timoshenko, "Methods of analysis of statical and dynamical stresses in rail," in Proceedings of the Second International Congress on Applied Mechanics, 1926, pp. 407-418. 
[8] G. Eason, "The stresses produced in a semi-infinite soild by a moving surface force," Int. J. Eng. Sci., vol. 2, pp. 581-609, 1965.

[9] V. V Krylov, "Generation of ground vibrations by superfast trains," Appl. Acoust., vol. 44, no. 2, pp. 149-164, 1995.

[10] V. V Krylov, "Vibrational impact of high-speed trains . I . Effect of track dynamics," J. Acoust. Soc. Am., vol. 100, no. 5, pp. 3121-3134, 1996.

[11] H. A. Dieterman and A. Metrikine, "The equivalent stiffness of a half-space interacting with a beam. critical velocities of a moving load along the beam," Eur. J. Mech. A/Solids, vol. 15, pp. 67-90, 1996.

[12] H. A. Dieterman and V. A. Metrikine, "Steady state displacements of a beam on an elastic half space due to a uniformly moving load," Eur. J. Mech. - A/Solids, vol. 16, no. 2, pp. 295-306, 1997.

[13] E. Kausel and J. M. Roësset, "Stiffness matrices for layered soils," Bull. Seismol. Soc. Am., vol. 71, no. 6, pp. 1743-1761, 1981.

[14] A. V Vostroukhov and A. V Metrikine, "Periodically supported beam on a viscoelastic layer as a model for dynamic analysis of a high-speed railway track," Int. J. Solids Struct., vol. 40, no. 21, pp. 5723-5752, 2003.

[15] K. L. Knothe and S. L. Grassie, "Modelling of railway track and vehicle/track interaction at high frequencies," Veh. Syst. Dyn., vol. 22, no. 3-4, pp. 209-262, 1993.

[16] X. Sheng and C. J. C. Jones, "Ground vibration generated by a load moving along a railway track," J. Sound Vib., vol. 228, no. 1, pp. 129-156, 1999.

[17] X. Sheng, C. J. C. Jones, and D. J. Thompson, "A theoretical model for ground vibration from trains generated by vertical track irregularities," J. Sound Vib., vol. 272, no. 3-5, pp. 937-965, 2004.

[18] X. Sheng, C. J. C. Jones, and M. Petyt, "Ground vibration generated by harmonic load acting on a railway track," J. Sound Vib., vol. 225, no. 1, pp. 3-28, 1999.

[19] A. Karlström and A. Boström, "An analytical model for train-induced ground vibrations from railways,” J. Sound Vib., vol. 292, no. 1-2, pp. 221-241, 2006.

[20] P. A. Costa, A. Colaço, R. Calçada, and A. S. Cardoso, "Critical speed of railway tracks. Detailed and simplified approaches," Transp. Geotech., vol. 2, pp. 30-46, Mar. 2015.

[21] X. Sheng, C. J. C. Jones, and D. J. Thompson, "Modelling ground vibration from railways using wavenumber finite- and boundary-element methods," Proc. R. Soc. A Math. Phys. Eng. Sci., vol. 461, no. 2059, pp. 2043-2070, Jul. 2005.

[22] S. François, M. Schevenels, P. Galvín, G. Lombaert, and G. Degrande, “A 2.5D coupled FE-BE methodology for the dynamic interaction between longitudinally 
invariant structures and a layered halfspace," Comput. Methods Appl. Mech. Eng., vol. 199, no. 23-24, pp. 1536-1548, 2010.

[23] Y. B. Yang and H. H. Hung, "A 2.5D finite/infinite element approach for modelling visco-elastic bodies subjected to moving loads," Int. J. Numer. Methods Eng., vol. 51, no. 11, pp. 1317-1336, 2001.

[24] Y. B. Yang, H. H. Hung, and D. W. Chang, "Train-induced wave propagation in layered soils using finite/infinite element simulation," Soil Dyn. Earthq. Eng., vol. 23, no. 4, pp. 263-278, 2003.

[25] R. Borja, W. Wu, and H. Smith, "Nonlinear response of vertically oscillating rigid foundations," J. Geotech. Eng., vol. 119, no. 5, pp. 893-911, 1993.

[26] W. Powrie, L. a Yang, and C. R. I. Clayton, "Stress changes in the ground below ballasted railway track during train passage," Proc. Inst. Mech. Eng. Part F J. Rail Rapid Transit, vol. 221, no. 2, pp. 247-262, Jan. 2007.

[27] L. A. Yang, W. Powrie, and J. A. Priest, "Dynamic Stress Analysis of a Ballasted Railway Track Bed during Train Passage," J. Geotech. Geoenvironmental Eng., vol. 135, no. 5, pp. 680-689, 2009.

[28] N. D. Beskou and D. D. Theodorakopoulos, "Dynamic effects of moving loads on road pavements: A review," Soil Dyn. Earthq. Eng., vol. 31, no. 4, pp. 547-567, Apr. 2011.

[29] T. Zaghloul, Sameh M, White, "Use of a three-dimensional, dynamic finite element program for analysis of fxexible pavement," Transp. Res. Rec. J. Transp. Res. Board, pp. 60-69, 1993.

[30] H. Lane, P. Kettil, and N.-E. Wiberg, "Moving finite elements and dynamic vehicle interaction," Eur. J. Mech. - A/Solids, vol. 27, no. 4, pp. 515-531, 2008.

[31] W. Zhai, Z. He, and X. Song, "Prediction of high-speed train induced ground vibration based on train-track-ground system model," Earthq. Eng. Eng. Vib., vol. 9, no. 4, pp. $545-554,2010$.

[32] Y. Shan, B. Albers, and S. a. Savidis, "Influence of different transition zones on the dynamic response of track-subgrade systems," Comput. Geotech., vol. 48, pp. 21-28, Mar. 2013.

[33] J. Wang, X. Jin, and Y. Cao, "High-speed maglev train-guideway-tunnel-soil modelling of ground vibration," Proc. Inst. Mech. Eng. Part F J. Rail Rapid Transit, vol. 226, no. 3, pp. 331-344, Oct. 2011.

[34] W. Gardien and H. G. Stuit, "Modelling of soil vibrations from railway tunnels," $J$. Sound Vib., vol. 267, no. 3, pp. 605-619, Oct. 2003.

[35] S. H. Ju, J. R. Liao, and Y. L. Ye, "Behavior of ground vibrations induced by trains moving on embankments with rail roughness," Soil Dyn. Earthq. Eng., vol. 30, no. 11, pp. 1237-1249, Nov. 2010. 
[36] S. H. Ju, "Finite element analysis of structure-borne vibration from high-speed train," Soil Dyn. Earthq. Eng., vol. 27, no. 3, pp. 259-273, Mar. 2007.

[37] J. Lysmer and R. L. Kuhlemeyer, "Finite dynamic model for infinite media," J. Eng. Mech., vol. 95, no. EM4, pp. 859-877, 1969.

[38] ABAQUS, “Abaqus Theory Manual v6.12,” 2013. .

[39] G. Kouroussis, O. Verlinden, and C. Conti, "Ground propagation of vibrations from railway vehicles using a finite/infinite-element model of the soil," Proc. Inst. Mech. Eng. Part F J. Rail Rapid Transit, vol. 223, no. 4, pp. 405-413, 2009.

[40] G. Kouroussis, L. Van Parys, C. Conti, and O. Verlinden, "Using three-dimensional finite element analysis in time domain to model railway-induced ground vibrations," Adv. Eng. Softw., vol. 70, pp. 63-76, Apr. 2014.

[41] G. Kouroussis, O. Verlinden, and C. Conti, "Free field vibrations caused by high-speed lines: Measurement and time domain simulation," Soil Dyn. Earthq. Eng., vol. 31, no. 4, pp. 692-707, Apr. 2011.

[42] D. Connolly, A. Giannopoulos, and M. C. Forde, "Numerical modelling of ground borne vibrations from high speed rail lines on embankments," Soil Dyn. Earthq. Eng., vol. 46, pp. 13-19, Mar. 2013.

[43] A. El Kacimi, P. K. Woodward, O. Laghrouche, and G. Medero, "Time domain 3D finite element modelling of train-induced vibration at high speed," Comput. Struct., vol. 118, pp. 66-73, Mar. 2013.

[44] L. Hall, "Simulations and analyses of train-induced ground vibrations in finite element models," Soil Dyn. Earthq. Eng., vol. 23, no. 5, pp. 403-413, Jul. 2003.

[45] Q. Fu and C. Zheng, "Three-dimensional dynamic analyses of track-embankmentground system subjected to high speed train loads.," Sci. World J., vol. 2014, pp. 1-19, 2014.

[46] P.-N. Thach, H.-L. Liu, and G.-Q. Kong, "Vibration analysis of pile-supported embankments under high-speed train passage," Soil Dyn. Earthq. Eng., vol. 55, pp. 92-99, Dec. 2013.

[47] G. Kouroussis, O. Verlinden, and C. Conti, "Finite-dynamic model for infinite media: corrected solution of viscous boundary efficiency," J. Eng. Mech., vol. 137, no. 7, pp. 509-511, 2011.

[48] R. L. Kuhlemeyer, "Finite element method accuracy for wave propagation problems," J. Soil Mech. Found. Div., vol. 99, no. 5, pp. 421-427, 1973.

[49] J. Lysmer, T. Ukaka, C. Tsai, and H. B. Seed, "FLUSH: A computer program for approximate 3-D analysis of soil-structure interaction problems," Berkeley, California, 1975. 
[50] A. Zerwer, G. Cascante, and J. Hutchinson, "Parameter Estimation in Finite Element Simulations of Rayleigh Waves," J. Geotech. Geoenvironmental Eng., vol. 128, pp. 250-261, 2002.

[51] H. Courant, R.; Friedrichs, K.; Lewy, "On the partial difference equations of mathematical physics," IBM J., vol. 11, pp. 215-235, 1967.

[52] C.-M. Nillson. and C. J. C. Jones, "Theory Manual for WANDS 2.1 Wave-NumberDomain FE-BE Software for Structures and Fluids,” 2007.

[53] J. Shih, D. Thompson, and A. Zervos, "Assessment of track-ground coupled vibration induced by high-speed trains," in The 21 st International Congress on Sound and Vibration, 2014, no. July, pp. 13-17.

[54] K. F. Graff, Wave Motion in Elastic Solids. Dover Publication, Inc., New York, 1975. 